\title{
Article
}

\section{The Se-S Bond Formation in the Covalent Inhibition Mechanism of SARS-CoV-2 Main Protease by Ebselen-like Inhibitors: A Computational Study}

\author{
Angela Parise ${ }^{1,2}$, Isabella Romeo ${ }^{1}\left[\right.$, Nino Russo ${ }^{1}\left[\right.$ and Tiziana Marino ${ }^{1, *(\mathbb{D}}$ \\ 1 Dipartimento di Chimica e Tecnologie Chimiche, Università della Calabria, Via Pietro Bucci, \\ 87036 Arcavacata di Rende, CS, Italy; angela.parise@unical.it (A.P.); isabella.romeo@unical.it (I.R.); \\ nino.russo@unical.it (N.R.) \\ 2 Institut de Chimie Physique UMR8000, Université Paris-Saclay, CNRS, 91405 Orsay, France \\ * Correspondence: tiziana.marino65@unical.it
}

Citation: Parise, A.; Romeo, I.; Russo,

N.; Marino, T. The Se-S Bond

Formation in the Covalent Inhibition Mechanism of SARS-CoV-2 Main Protease by Ebselen-like Inhibitors: A Computational Study. Int. J. Mol. Sci. 2021, 22, 9792. https://doi.org/ $10.3390 /$ ijms22189792

Academic Editor: József Tőzsér

Received: 12 August 2021

Accepted: 7 September 2021

Published: 10 September 2021

Publisher's Note: MDPI stays neutral with regard to jurisdictional claims in published maps and institutional affiliations.

Copyright: (c) 2021 by the authors. Licensee MDPI, Basel, Switzerland. This article is an open access article distributed under the terms and conditions of the Creative Commons Attribution (CC BY) license (https:// creativecommons.org/licenses/by/ $4.0 /)$.

\begin{abstract}
The inhibition mechanism of the main protease (Mpro ${ }^{\text {) }}$ of SARS-CoV-2 by ebselen (EBS) and its analog with a hydroxyl group at position 2 of the benzisoselenazol-3(2H)-one ring (EBS-OH) was studied by using a density functional level of theory. Preliminary molecular dynamics simulations on the apo form of Mpro were performed taking into account both the hydrogen donor and acceptor natures of the $\mathrm{N} \delta$ and $\mathrm{N} \varepsilon$ of His41, a member of the catalytic dyad. The potential energy surfaces for the formation of the Se-S covalent bond mediated by EBS and EBS-OH on Mpro are discussed in detail. The EBS-OH shows a distinctive behavior with respect to EBS in the formation of the noncovalent complex. Due to the presence of canonical H-bonds and noncanonical ones involving less electronegative atoms, such as sulfur and selenium, the influence on the energy barriers and reaction energy of the Minnesota hybrid meta-GGA functionals M06, M06-2X and M08HX, and the more recent range-separated hybrid functional $w B 97 X$ were also considered. The knowledge of the inhibition mechanism of Mpro by the small protease inhibitors EBS or EBS-OH can enlarge the possibilities for designing more potent and selective inhibitor-based drugs to be used in combination with other antiviral therapies.
\end{abstract}

Keywords: SARS-CoV-2 main protease; DFT; inhibition mechanism; Se-S covalent bond; potential energy surface

\section{Introduction}

Since early 2020 the whole world has been trying to face the severe acute respiratory syndrome coronavirus 2 (SARS-CoV-2) [1,2]. With a relatively long incubation period along with symptoms characterized by different levels of severity, the disease is still affecting billions of people and spreading in an unrelenting fashion causing widespread health, social, and economic disruption. Despite originating from the same Coronaviridae family as the Middle East Respiratory Syndrome (MERS) and Severe Acute Respiratory Syndrome (SARS) the shared sequence similarity is $~ 80 \%$ [2]. Viruses belonging to the genus Coronavirus are zoonotic and characterized by positive-stranded RNA encapsulated by a membrane envelope of 300-400 $\mathrm{nm}$ [3]. The morphology of virions is similar to a crown due to the mushroom-shaped proteins called spike glycoproteins (S proteins) responsible for the host tropism [4]. Human infections caused by the SARS coronavirus are distinguished by the interaction between the S-protein and the human angiotensin-converting enzyme 2 (ACE2); highly expressed on epithelial cells of the respiratory tract [5]. Following host cell entry, the viral single-stranded RNA is released for replication and translation of the virus polyproteins that are processed by two cysteine proteases (CPs), papain-like protease $\left(\mathrm{PL}^{\mathrm{pro}}\right)$ and a main protease $\left(\mathrm{M}^{\mathrm{pro}}\right)$ also known as 3-Chymotrypsin-like protease $\left(3 \mathrm{CL}^{\text {pro }}\right)[6,7]$. Mpro acts in the immune regulation and cleavage of the polyprotein at eleven 
different sites generating nonstructural proteins, such as RNA polymerase, endo- and exoribonuclease, which are relevant in the replication process of the virus [8]. Considering that $\mathrm{M}^{\text {pro }}$ is only found in the virus rather than in the host cell, this protein represents an interesting target for the development of new promising anticoronavirus therapeutic agents [6,7]. Structurally, SARS-CoV-2 $\mathrm{M}^{\text {pro }}$ forms a homodimer (protomer A and B) and each protomer consists of three domains: domain I (residues 8-101), domain II (residues 102-184), and domain III (residues 201-303) which are connected by a loop region (residues 185-200) [6,7]. In $\mathrm{M}^{\text {pro }}$, the catalytic dyad consisting of His41 and Cys145 is located in the cleft between domains I and II $[9,10]$. The main aim of this protein is cleaving the polyprotein ppla and pplab translated from the viral RNA at 16 different positions to generate important structural proteins in addition to nanostructural proteins (NSPs) which are involved in arresting the process of viral assembly in the replication cycle [11]. The presence of a reactive sulphur in the active site of cysteine proteases provides a target for the design of many covalent and noncovalent inhibitors [11-15]. Among the in vitro investigated covalent inhibitors, it was observed that ebselen [(2-phenyl-1,2-benzoisoselenazol-3(2H)one], (EBS) shows stronger inhibition against the SARS-CoV-2 virus than N3, the known Michael acceptor inhibitor [15-19]. EBS is a low-molecular-weight organoselenium drug having a pleiotropic mode of action and because of its very low toxicity has encountered no barriers for use in humans [19-21]. In fact, in the pre-COVID-19 era, EBS was known as a mimic of glutathione peroxidase and inhibits several enzymes involved in inflammatory processes, such as lipoxygenases, NO synthases and NADPH, providing it with remarkable anti-inflammatory, antiatherosclerotic and cytoprotective properties [22,23]. EBS is known to act as potent inhibitor of proteins implicated in the biosynthesis of the mycobacterial cell wall $[20,24]$ by covalently modifying a noncatalytic cysteine through the reversible oxidation of the $\gamma$-sulfur of the amino acid by the EBS selenium, while in the case of $\mathrm{M}^{\text {pro }}$, the cysteine target of ebselen is crucial for its protease activity [25]. In this system there is evidence arising from experimental study that the cysteine residue involved is present in the catalytic site (Cys145) [15]. Furthermore, EBS has also shown preclinical efficacy for cisplatin-induced ototoxicity $[26,27]$ and has been considered for the treatment of bipolar disorders and hearing loss [28]. EBS inhibition properties have been evaluated in different clinical trials, exhibiting its safety in humans due to its extremely low cytotoxicity $[29,30]$ and therefore it provides the promise of drug repurposing. On the basis of these preclinical studies the reaction of ebselen was reported with cysteine residues from completely unrelated proteins including the C-terminal domain of the HIV-1 capsid, Mycobacterium tuberculosis transpeptidase LdtMt2, glutamate dehydrogenase, Clostridium difficile toxins, Mycobacterium tuberculosis antigen 85C enzyme and many others [20,31-36]. Ebselen and some of its synthesized analogues were found to inhibit both SARS-CoV-2 Mpro and PL pro $[37,38]$. Repurposing of known drugs can provide an accelerated path for approval and a likely option to address the current COVID-19 pandemic. In particular, EBS has displayed inhibition against the M ${ }^{\text {pro }}$ of SARS-CoV-2 virus with the concentration required to produce $50 \%$ of the maximum possible effect and indicating antiviral activity in cells, the EC50, equal to $4.67 \mu \mathrm{M}$; superior to that of $\mathrm{N} 3(16.77 \mu \mathrm{M})$ [15]. Furthermore, the improvement of the inhibitory potency of the ebselen derivative obtained by the hydroxyl group in the position ortho of the N-phenyl ring (EBS-OH of Scheme 1) on the other Achilles' heel SARS-CoV-“ PL ${ }^{\text {pro }}$, induced us to investigate the Mpro inhibition mechanism by both EBS and EBS-OH inhibitors [21,39]. The behavior of the heavier chalcogens, $\mathrm{S}$ and $\mathrm{Se}$, in biological systems has only recently gained more attention, in particular Se has been shown to form an Se-S intermediate in selenoprotein reductase and formate dehydrogenase. They play a central role in the enzyme's activation $[40,41]$ and also in deiodinase biomimetics [42]. So far the SARS-CoV-2 Mpro inhibition mechanism has been studied by using Michael acceptor and peptidomimetic inhibitors at the QM-MM level of theory [43-47]. So, the mechanistic understanding of the Se-S covalent bond formation promoted by inhibitors, such as EBS and EBS-OH in the present study, could contribute to 
enlarge the molecular inhibition mechanism of SARS-CoV-2 $\mathrm{M}^{\text {pro }}$ and stimulate the design of other similar drugs.

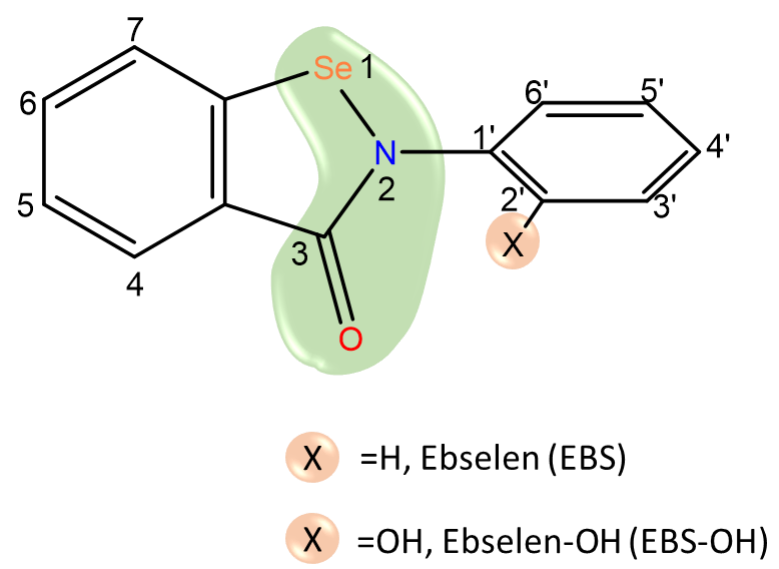

Scheme 1. Sketch of ebselen, $X$ group in position ortho of the phenyl ring can be $\mathrm{H}$ (EBS) or OH (EBS-OH). Ebselen warhead is evidenced in green.

Moreover, stimulated by the most recent literature regarding the inhibition mechanism of $\mathrm{M}^{\text {pro }}$ enzyme $[43,45-47]$ we took into account the protonation state of the catalytic histidine (His41) [43,48,49]. Therefore, we have also performed computational simulations by using molecular docking and classical molecular dynamics (cMD) devoted to accurately model the structure and dynamics of $\mathrm{M}^{\text {pro }}$ in both the $\mathrm{N} \delta$ and $\mathrm{N} \varepsilon$ protonated states of His41 to better evaluate their eventual influence on the covalent inhibition process by EBS. For clarity, $\mathrm{M}^{\text {pro }}$ in the $\mathrm{N} \delta$ form will in the whole manuscript be named $\mathrm{M}^{\text {pro }}-\mathrm{HID}$ and $\mathrm{M}^{\mathrm{pro}}$ in the $\mathrm{N} \varepsilon$ form will be $\mathrm{M}^{\text {pro }}$-HIE. To shed light into the inhibition mechanism of EBS and EBS-OH, the potential energy surfaces (PES) for the formation of the covalent complex between SARS-CoV-2 Mpro and the two considered inhibitors have been calculated and analysed, considering the effects of the dielectric value, $\varepsilon=80$ and $\varepsilon=4$, for the water and protein environments, respectively. In the case of EBS-OH only the inhibition mechanism by $\mathrm{N} \delta$-His 41 was performed. The calculated PES for the two inhibitors can be used to determine whether, and to what extent, a covalent inhibitor is reversible or not. This knowledge is important in order to provide in the near future, additional leads for covalent inhibitors obtained by incorporating small-molecules, such as EBS and EBS-OH, into hybrid molecules which also have few side effects. In addition, the ability of other DFT functionals ( $\omega$ B97X, M06, M06-2X and M08-HX) as single points on the B3LYP-D3 optimized geometries were tested to obtain more accurate data for the energy barriers and reaction energy of the inhibition mechanism driven by the sulfur-selenium covalent bond formation.

\section{Results}

In an effort to better understand the molecular mechanisms involved in the inhibition of $\mathrm{M}^{\text {pro }}$, many works have focused on classical Molecular Dynamics simulations with $[12,14,25,48-50]$ and without $[11,51]$ inhibitors. In the present investigation cMD simulations performed on apo $\mathrm{M}^{\text {pro-HID }}$ and $\mathrm{M}^{\text {pro-HIE }}$ represent a preliminary step useful to obtain comparative structural and dynamic properties to deeply describe EBS and EBS-OH inhibition mechanisms.

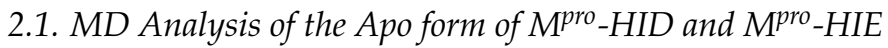

SARS-CoV-2 Mpro has been well characterized by crystallography. So far about 1000 entries of X-ray crystal structures for SARS-CoV-2 M ${ }^{\text {pro }}$ are present on the Protein Data Bank in an apo form or a complexed one [15,51-55]. To better evaluate the effects on the structural properties in the catalytic pocket, the starting crystal structure with the PDB code 
6W63 [56] was used for cMD simulations considering the apo form and the complexed one with EBS in both the $\mathrm{N} \delta$ and $\mathrm{N} \varepsilon$ protonation states of the His41. The Cys145 residue was considered in the neutral form. As previously suggested [49], these investigations are helpful to monitor what happens during the simulation time in the His41-Cys145 catalytic dyad region, allowing us to better rationalize eventual changes in the shape of the inhibitor catalytic site and their possible influence on the explored inhibition mechanism of EBS $[48,57]$.

To compare the dynamic behavior of $M^{p r o}-N \delta$ and $M^{\text {pro }}-\mathrm{N} \varepsilon$, several properties were taken into account: root mean square deviation (RMSD); RMSD-based clustering; root mean square fluctuation (RMSF), solvent accessible surface area (SASA), radial distribution function (RDF), volume of the binding pocket, salt bridges and the H-bond between residues. Results are reported in Figures S1-S9.

The analysis of the calculated RMSD for the residue pair Cys145-His41 in both the $\mathrm{N} \delta$ and $\mathrm{N} \varepsilon$ forms (shown in Figure S3) allows us to observe that the spatial orientation of the dyad remains constant during the simulation time in the case of His41-N $\delta$, while a dissimilar trend assumes the RMSD value of His41-N $\varepsilon$. The major fluctuations observed in RMSD for His41-N $\varepsilon$ could suggest different conformations of the Cys145 side chain also previously found in the ortholog protease of SARS-CoV $[46,58]$.

A different behavior may also be noticeable in the trend of RMSF (see Figure S4) where it is evident that mainly domain I (residues 1-100) and III (residues 200-300) suffer a major rearrangement revealing higher mobility.

From the superposition of the most representative structure derived from RMSDbased clustering (Figure S2 and Table S4) of the MD trajectory of SARS-CoV-2 MPro-HID and HIE (Figure 1), it is possible to see no appreciable difference in the secondary structure except for the chain related to residue His41, that in $\mathrm{M}^{\mathrm{pro}}$-HID is organized in a longer alpha-helix including Arg40-His41-Val42-Ile43-Cys44 versus Arg40-His41-Val42 present

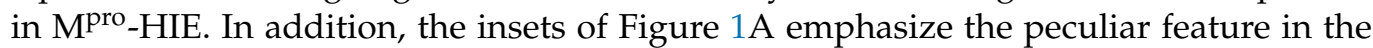
catalytic dyad: the altered rotational state of His41 along with the different conformation of the side chain of $\mathrm{Cys} 145$. In fact, the $\mathrm{C}=\mathrm{O}-\mathrm{C}_{\alpha}-\mathrm{C}_{\beta}-\mathrm{S}_{\gamma}$ torsional angle adopts a trans-like conformation $\left(-149.15^{\circ}\right)$ in $\mathrm{M}^{\text {pro }}$-HID and a gauche-like one $\left(50.69^{\circ}\right)$ in $\mathrm{M}^{\text {pro }}$-HIE.
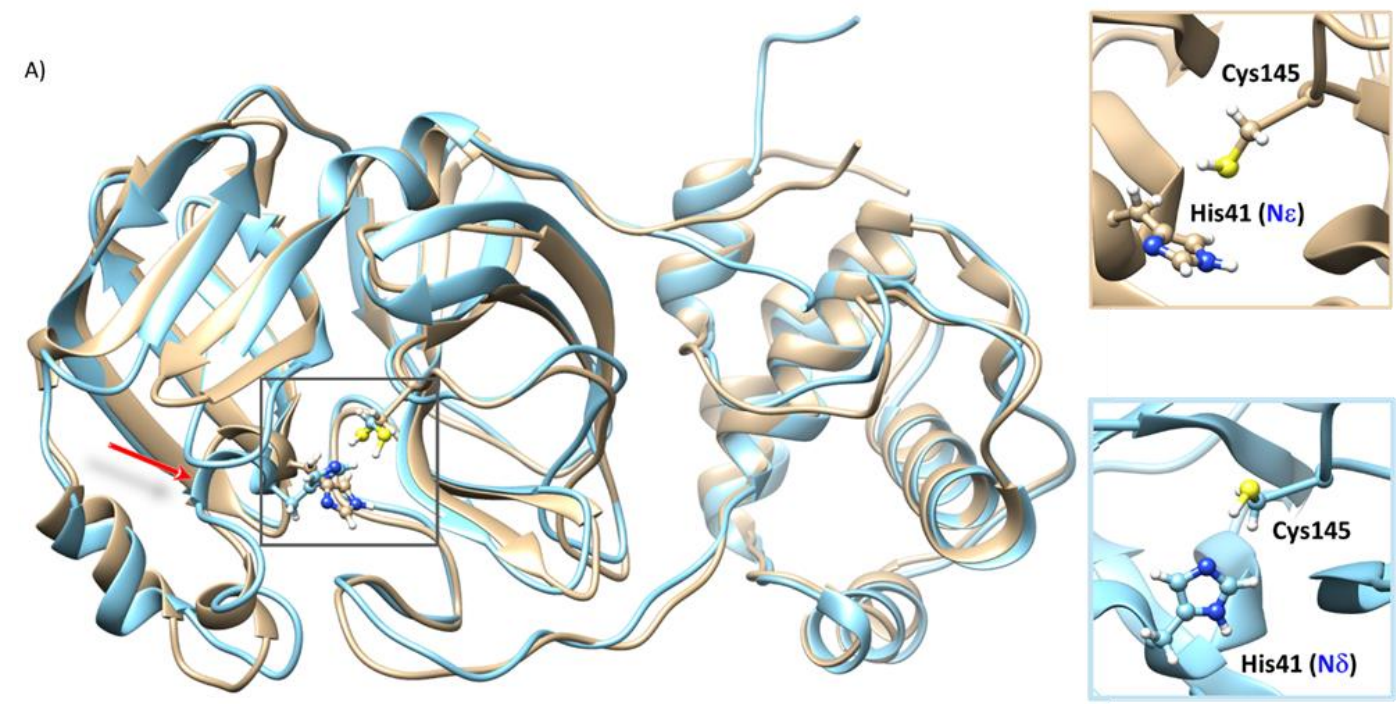

Figure 1. Cont. 


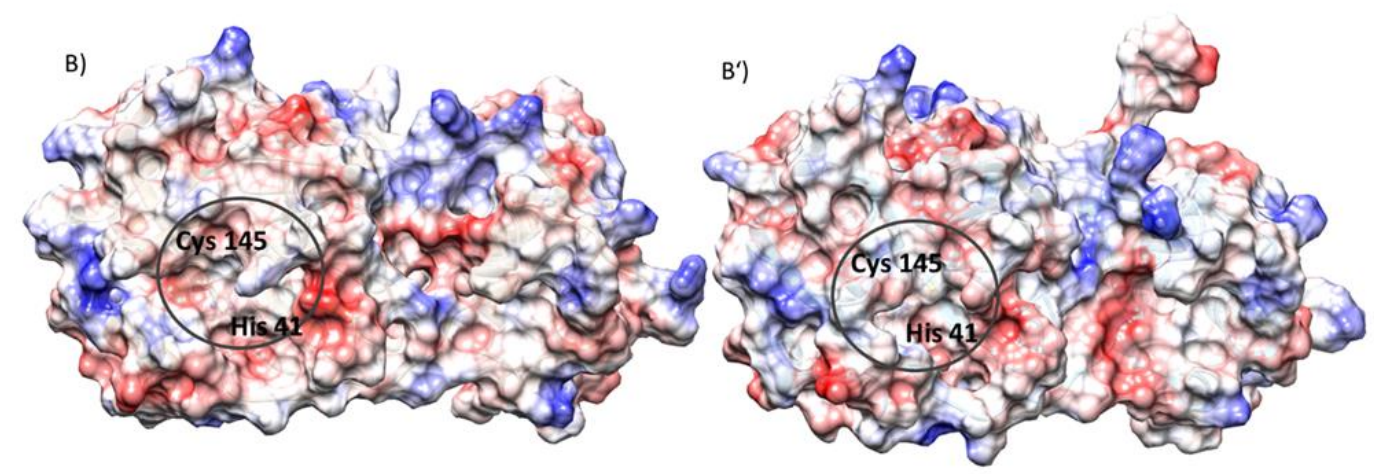

Figure 1. (A) Alignment of the most representative structure of the SARS-CoV-2 Mpro_HID (cyan) and SARS-CoV-2 MPro HIE (gold), as obtained from a cluster analysis along the molecular dynamics trajectories. The insets evidence the structural organization inside the catalytic dyad (His41-Cys145). (B,B') Electrostatic potential surface (APBS) in the SARS-CoV-2 $\mathrm{M}^{\text {pro }}$-HID (B) and SARS-CoV-2 Mpro HIE (B').

Furthermore, the comparison of the electrostatic potential, shown in Figure 1B, $\mathrm{B}^{\prime}$, calculated for both protonation states of His 41 by solving the Poisson-Boltzmann equation as implemented in the APBS code [59], reveals a more marked distribution of negative regions on the surface in proximity to the catalytic site of the SARS-CoV-2 M ${ }^{\text {pro }}$ HID. Moreover, the catalytic pocket volume changes dependently on $\mathrm{M}^{\text {pro-HID }}$ or $\mathrm{M}^{\text {pro }}$-HIE (see Figure S5). Similar active site flexibility has been previously highlighted by Pavlova et al. [48].

\subsection{Covalent Inhibition}

Jin et al. [15], applying a screening strategy on over 10,000 inhibitors of the SARSCoV-2 virus main protease identified EBS as a good candidate, revealing through tandem MS/MS analysis, its ability to covalently bind to the cysteine 145 residue of $\mathrm{M}^{\text {pro }}$. Due to the observed stronger inhibition, they did not exclude the possibility that it can also act as a noncovalent inhibitor [15].

As reported in Scheme 2 the inhibition usually takes place in two steps. The compound must first bind noncovalently to the target protein, placing its moderately reactive electrophilic selenyl amide moiety, the warhead in ebselen (as circled in Scheme 1), close to the nucleophile (Cys145) of $\mathrm{M}^{\text {pro }}$ and giving rise to the enzyme-inhibitor complex (EI), in which the binding free energy $\left(\Delta G_{\text {bind }}\right)$ depends only on noncovalent interactions and is related to the inhibition constant $\mathrm{Ki}$. In the second stage a chemical reaction transforms the EI complex generating the final covalent complex (E-I). In the case of EBS this mechanism is proposed by MS/MS study [15]. Irrespective of the exothermicity, if high reverse reaction barriers are observed the bond formation is effectively irreversible, so $\mathrm{k}_{-2}$ will be zero (see Scheme 2).

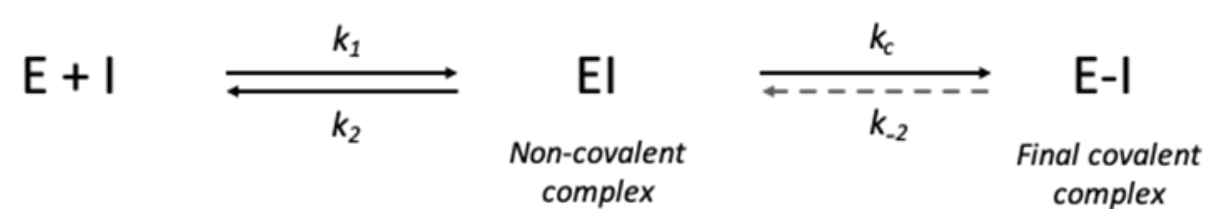

Scheme 2. General scheme of covalent interaction between a small molecule and its target.

\subsubsection{Ebselen (EBS) and Its Derivative (EBS-OH)}

The knowledge of the inhibition mechanism at an atomistic level represents a crucial step in the pathway of drug design since it allows us to characterize the reaction path, including characterization of the transition state species which are undetectable at an experimental level. The investigation also extended to EBS-OH which may prove helpful to better understand if this kind of ebselen derivative can improve the selectivity action, a feature actually not present in ebselen $[15-19,21]$. As above mentioned, the additional 
hydroxyl group in the position ortho of the phenyl ring resulted in an increase of the inhibitory potency of ebselen by one order of magnitude [21].

The electrostatic potential maps (MEPs) of the two molecules, shown in Figure 2, enable us to visualize the charge distributions and charge related properties of the two molecules.
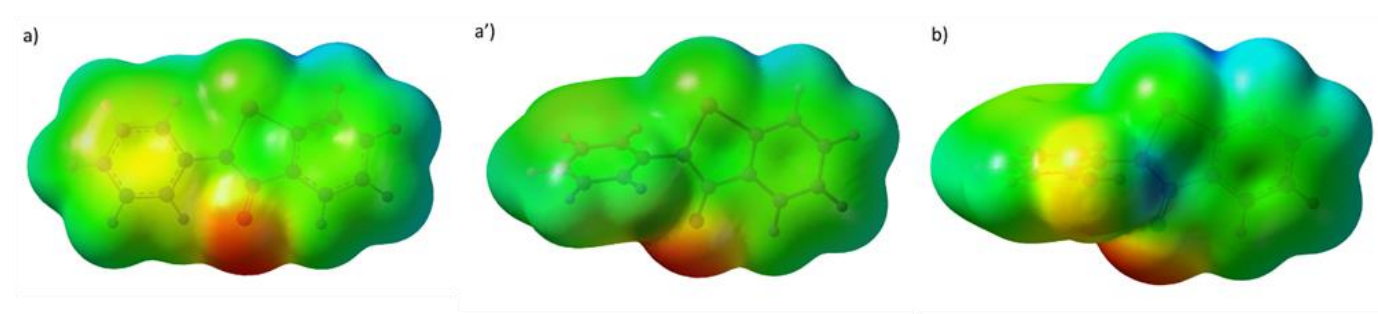

$-0.07=0.07$

Figure 2. Molecular electrostatic potential (MEP) of: (a) planar EBS; (a') nonplanar EBS and (b) EBS-OH geometries optimized at B3LYP/6-31+G level of theory.

It is possible to remark that the presence of an $\mathrm{OH}$ moiety on the position ortho of the $\mathrm{N}$-phenyl ring of EBS introduces a redistribution of the charge that can be fruitful in the course of the inhibition mechanism. The NBO charge values collected in Table S6 underline a major variation on the selenyl amide moiety. In particular, the nitrogen $\left(\mathrm{N}_{2}\right)$ becomes more negative ( -0.661 e vs. -0.602 e in EBS) and the oxygen $\left(\mathrm{O}_{3}\right)$ decreases its charge $\left(-0.597\right.$ e vs. -0.618 e in EBS). Furthermore, the charges on $\mathrm{C}^{\prime}, \mathrm{C}^{\prime}$ and $\mathrm{C}^{\prime}$ reflect the effect of $\mathrm{OH}$ as an activating group on $\mathrm{C}^{\prime}$ (ortho) and $\mathrm{C}^{\prime}$ (para), while as a deactivating one on $\mathrm{C}^{\prime}$ (meta) with respect to EBS.

Inside the catalytic pocket, EBS tends to assume a folded-like conformation with almost isoenergetic results $\left(\sim 0.32 \mathrm{kcal} \mathrm{mol}^{-1}\right)$ to the totally planar one (see Figure 2$)$. It is possible to note that the charge distribution suffers a small modification if compared with the extended conformation, but is still different from that of EBS-OH, evidencing again the role played by its hydroxyl group on the $\mathrm{N}$-phenyl ring.

\subsubsection{Determination of the Inhibitor-M $\mathrm{M}^{\text {pro }}$ Complex}

The most representative structure of the $\mathrm{M}^{\text {pro }}$-HID and $\mathrm{M}^{\text {pro }}$-HIE, obtained from the clustering MDs trajectory (Figure S2 and Table S4), was used in the next docking simulations with EBS and EBS-OH. Details of the procedure used are given in the Electronic Supplementary Materials.

The best docked poses $\mathrm{M}^{\text {pro }}$-HID-EBS, Mpro-HIE-EBS and $\mathrm{M}^{\text {pro-HID }-E B S-O H}$ (shown in Figure S11) were employed, after solvation and MM minimization, as the starting point for building the active site model.

Active site model: The QM cluster model of the active site was derived following a well consolidated procedure [60-63]. The model includes: Pro39, Arg40, Val42, Ile43, Cys44, Phe140, Leu141, Asn142, Gly143, Ser144, His163, Met165, Glu166, Leu167, the catalytic dyad His41/Cys145, EBS, W1 and W2 (see Figure 3). Following the indications from the literature [46] and from our cMD results (Figure S8 and Tables S2 and S3), the Asp187 residue was not included in the model since its involvement in a salt bridge with Arg40 precluded its participation in the inhibition mechanism. As usually requested by the QM cluster model [64-66], the amino acid residues were truncated as shown in Figure 3, and the coordinates of the related selected atoms were fixed (indicated by stars) during geometry optimizations to prevent unrealistic movements of residues at the active site. In spite of this, the size of the model used in the present study was large enough to grant the flexibility required for the active site groups during the chemical events of the inhibition process. The model thus consists of 312 or 313 atoms including EBS or EBS-OH, respectively. In all the studied systems, the overall charge of the model is zero. 


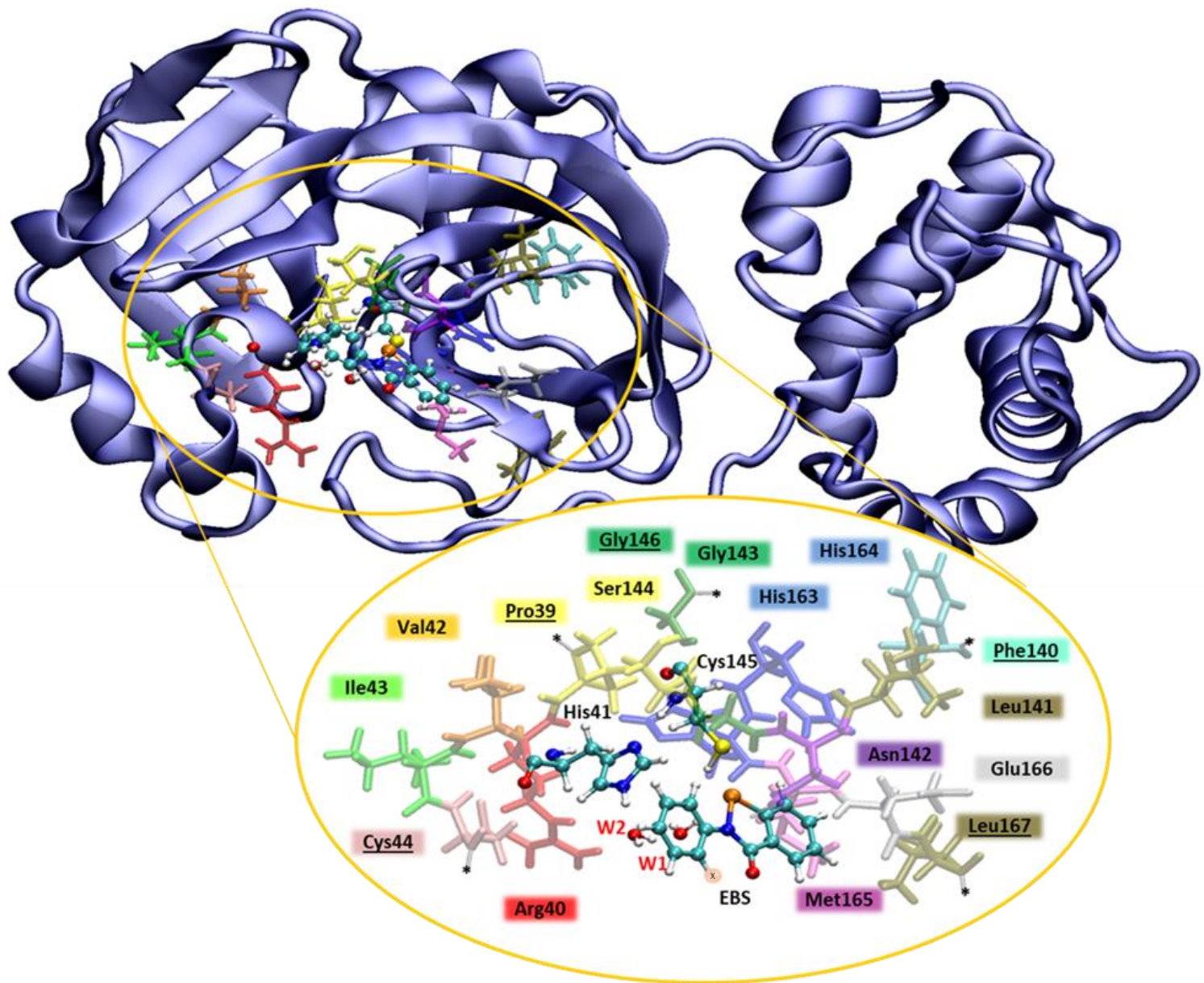

Figure 3. $M^{\text {pro }}$ cartoon representation. In the yellow circle the QM-cluster model of 312(3) atoms for EBS (EBS-OH). Amino acid residues are shown in sticks and colored by residue name, the catalytic dyad (Cys145, His41), EBS and water molecules W1 and W2 are in balls and sticks. Stars on residues Pro39, Cys44, Phe140, Gly146 and Leu167 point to frozen atoms and delimit the model truncations.

From the plot of solvent accessible surface area at the catalytic pocket (see Figure S6), we can note a smaller area in the case of Mro-HID.

From the water radial distribution function (RDF) analysis, obtained as a function of the distance between the water oxygen and side chains of Cys145 and His41 (black and purple line in Figure S9), a different water distribution can be noted in both Mpro-HID and -HIE, in the first solvation shell of His41, while a similar distribution takes place in that of Cys145. Furthermore, the two water molecules (W1 and W2) are engaged in an extensive network of H-bonds between them and with the His41 imidazole ring. Such behavior confirms that due to the presence of a catalytic dyad (Cys145 and His41) in Mpro $[8,67,68]$, and differently from other cysteine and serine proteases where an Asp/Glu acts as the third catalytic residue, a buried water molecule plays a catalytic role.

\subsection{Inhibition Mechanism}

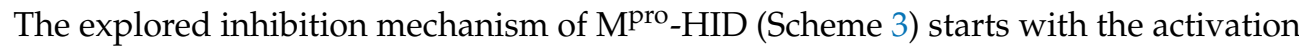
step that takes place from a proton shift between the thiol of Cys145 and the $\mathrm{N} \varepsilon$ of the imidazole of His41, affording the Cys-His salt bridge present in the intermediate EI' adduct. 


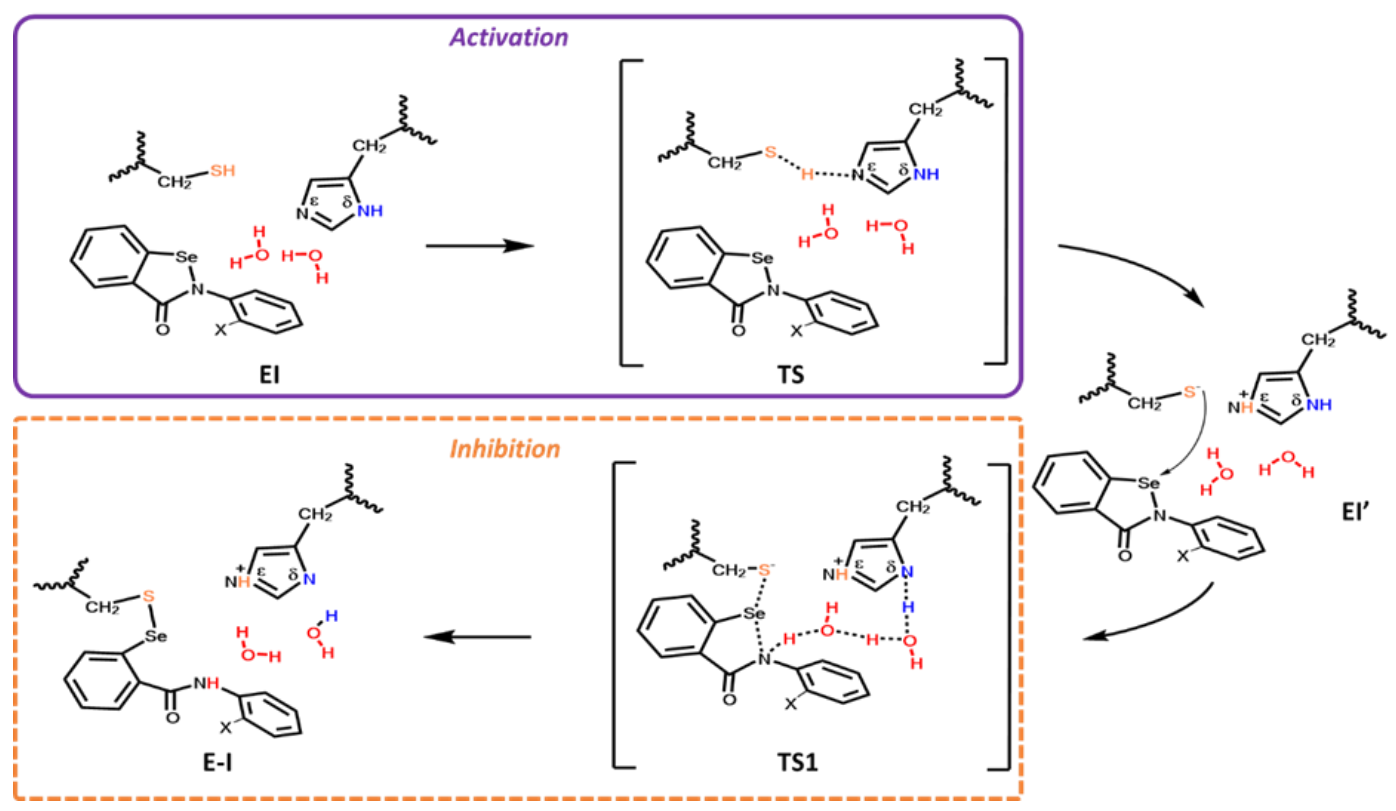

Scheme 3. Proposed mechanism for the covalent inhibition of Mpro SARS-CoV-2 for HID by EBS in two phases: activation (in violet) and inhibition through covalent bond formation (in dashed orange). $\mathrm{X}$ indicates $\mathrm{H}$ for EBS and $\mathrm{OH}$ for $\mathrm{EBS}-\mathrm{OH}$.

In this way the highly nucleophilic thiolate anion is formed. This step is very crucial for catalysis performed by CPs [69]. The formed efficient nucleophile $-\mathrm{CH}_{2} \mathrm{~S}^{(-)}$thiolate, is now able to perform the nucleophile attack on the selenium (TS1) with the formation of a new selenylsulfide bond and the concomitant ring opening, also as result of the water-mediated proton delivery on behalf of His41, finalizing the covalent inhibition (E-I).

Contrary to what occurred in previous theoretical studies on proteolysis and on the inhibition of other CPs [70-72] and in agreement with a more recent work [45], both Cys145 and His41 residues of the catalytic dyad are in the neutral form.

Further indications on the protonation states of the $\mathrm{M}^{\mathrm{pro}}$ residues comes from $\mathrm{pKa}$ values predicted using $\mathrm{H}++$ computations [73] (Table S1). In fact, the pKa of the Cys145 buried in the active site appears to be lowered with respect to its intrinsic $p K a \approx 8.6$ at $\mathrm{pH}=7$ [74], due to interaction with the nearby histidine residue, as has often been found in other CPs for catalytic cysteines $[75,76]$. Such an alteration of the intrinsic pKa value in the enzyme active site is usually a consequence of the local electronic environment generated by interactions involving the functional groups in the side chains of amino acids as well as the substrate, as documented in many serine protease members $[77,78]$. Such a scenario is well depicted in the EI optimized complexes referred to for EBS for both the HID and HIE forms (Figure 4), exhibiting the -SH group of Cys145 fruitfully oriented towards the imidazole of His41 and engaged in other different interactions.

In fact, the related noncovalent interaction (NCI) plots (Figure 5) evidence that the region including the catalytic dyad is characterized by the presence of strong and attractive $\mathrm{H}$-bonds, while the van der Waals contributions appeared more pronounced in the case of the HIE form for EBS due to the planar arrangement assumed by EBS, in this case with respect to that in the HID one. In Figure 5 the NCI analysis of EI in the $\mathrm{M}^{\text {pro }}$-HIE reveals a set of complex interactions between EBS and the amino residues of the catalytic pocket, which arise from a combination of specific hydrogen bonds (atom-atom interactions) with broader surfaces indicative of stabilizing vdW interactions, as a consequence of the planar conformation. In addition, we underline the presence of an interaction between selenium with the thiol group acting as donor of electron density typical of the chalcogen bond. This was more pronounced in the HID form ( $3.54 \AA$ ) than in the HIE one (4.00 $\AA$ ) as also evidenced by the more extended isosurfaces of the NCI (Figure 5). These findings confirm that noncovalent interactions are of pivotal importance in controlling molecular recognition phenomena. In both $\mathrm{M}^{\text {pro-HID }}$ and HIE the water molecules trapped inside the active site 
span the distance from the $\mathrm{N} \varepsilon(\delta)$ of His41 and nitrogen of the selenyl amide moiety with typical H-bond values as shown in Figure 4.

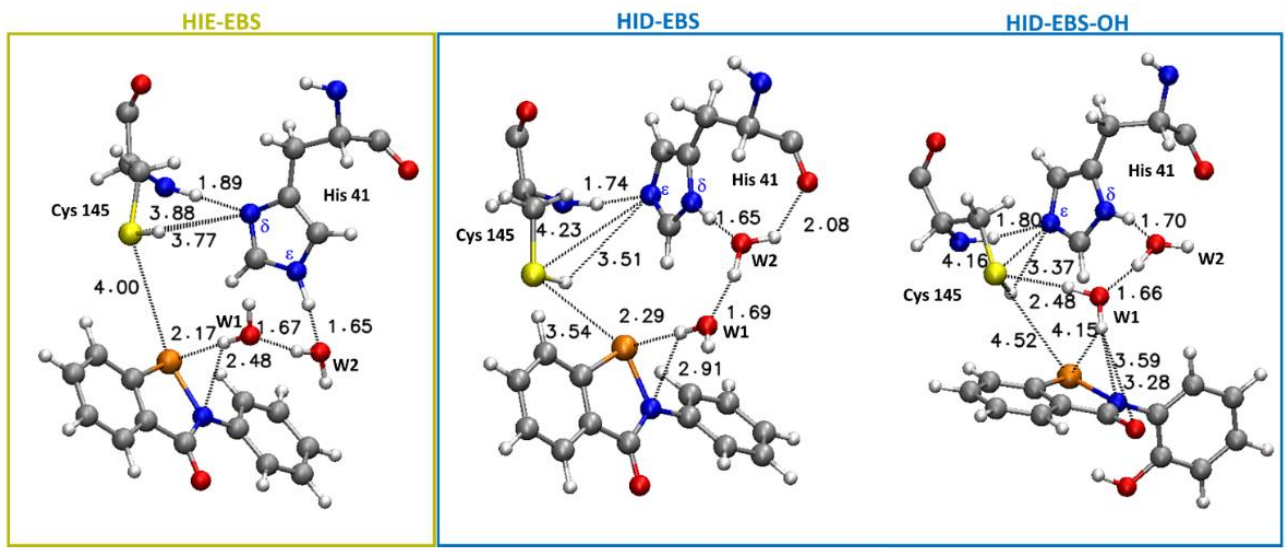

Figure 4. Structure and main distances (in $\AA$ ) between atoms of the Mpro active site and EBS in the EI complex for both HIE (in yellow box) and HID forms and between atoms of the $\mathrm{M}^{\text {pro }}$ active site HID and EBS-OH (in blue box) optimized at the B3LYP-D3/6-31+G (2d,2p) level. For clarity, only a small part of the model is shown. For the full model, see Figure 3.
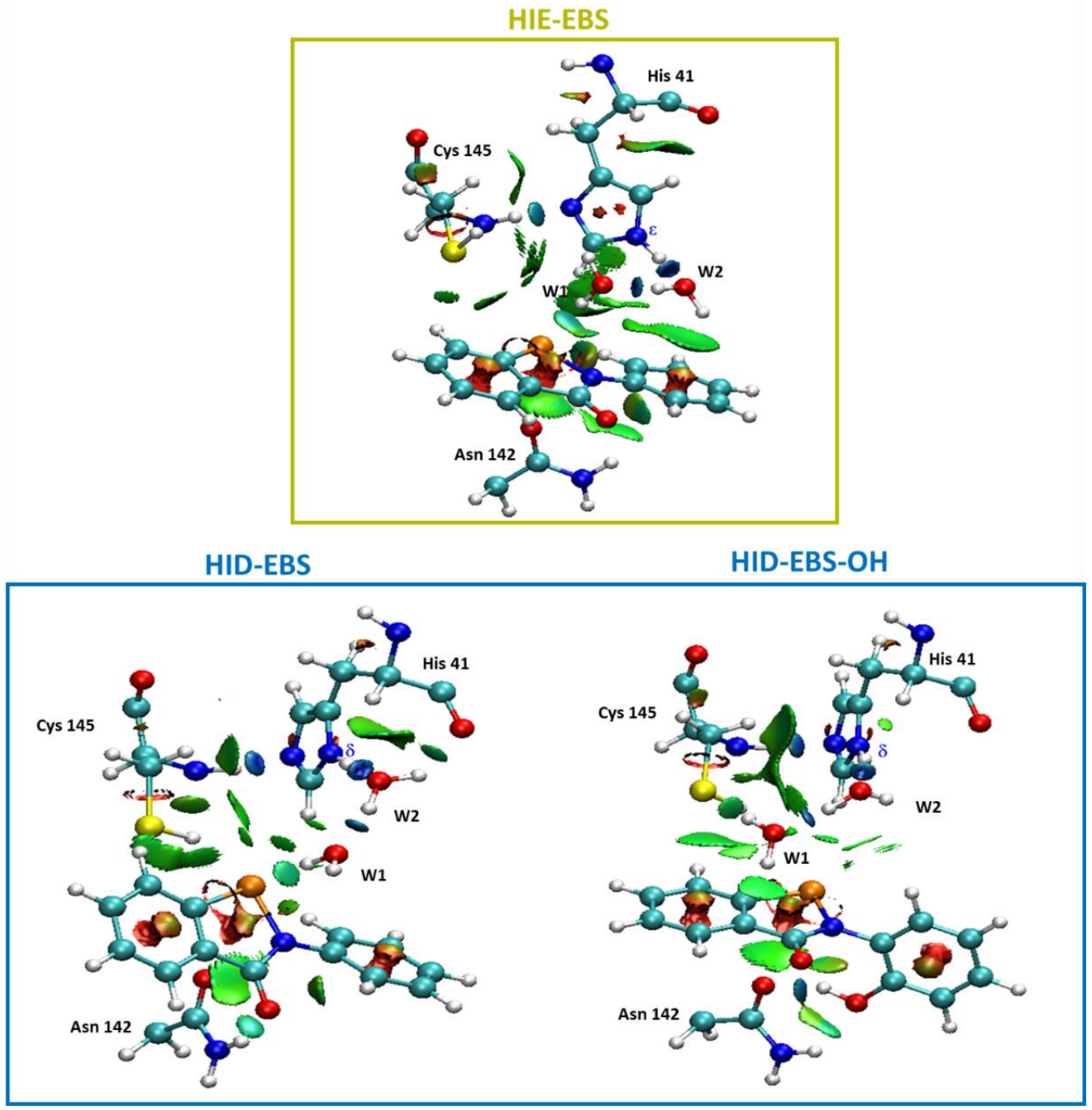

Figure 5. Noncovalent interaction plot calculated for the stationary point EI of the $\mathrm{M}^{\text {pro }}$-HIE inhibition process promoted by EBS (in yellow box). Mpro-HID inhibition process promoted by EBS and EBS-OH (in blue box). For clarity, only relevant residues were kept. 
When EBS-OH is considered, the torsion angle $\Phi$ between two planes twists the biphenyl-like system to be perpendicular $\left(\Phi 84.5^{\circ}\right)$, driven also by the formation of an $\mathrm{H}-$ bond between the $\mathrm{OH}$ substituent with the carbonyl side chain of the Asn142 present in the catalytic pocket (see Figure 5). NCI analysis clearly shows how the twisted conformation of the EBS-OH molecule results in a better fitting of the geometry of the active site. In the catalytic pocket of the $\mathrm{M}^{\text {pro }}$-HID, the EBS assumes a less accentuated twisted conformation $\left(\Phi-42.7^{\circ}\right)$ than that in EBS-OH, but more evident than that in EBS in $\mathrm{M}^{\text {pro }}-\mathrm{HIE}\left(\Phi-16.8^{\circ}\right)$.

\subsubsection{Inhibition Promoted by EBS}

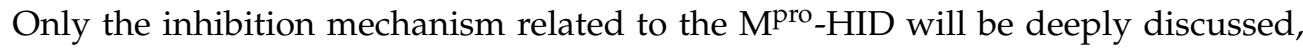
while details referring to $\mathrm{M}^{\text {pro-}}$-HIE are given in the Supplementary Materials (Figure S14 and S15, Table S8). Starting from the EI structure, reported in Figure 4, the first step of the reaction concerns the activation of the neutral cysteine thiol group to generate the thiolate one. This takes place by the formation of the transition state, TS (Figure 6). This transition state clearly depicts the activation of the $-\mathrm{SH}$ nucleophile center where the His41 acts as a

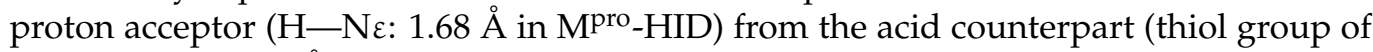
Cys145), S-H: $1.47 \AA$ in HID. Analysis of the obtained imaginary frequency (Figure 7 and Figure S14) confirms this process. The distance between the sulfur and selenium of EBS is reduced ( $3.20 \AA$ and $3.05 \AA$ ) with respect to the reactant EI, where it assumes the value of $4.00 \AA$ and $3.54 \AA$ in $\mathrm{M}^{\text {pro }}$-HIE and $\mathrm{M}^{\text {pro }}$-HID, respectively. The related activation energy is found to be $9.1 \mathrm{kcal} \mathrm{mol}^{-1}$ in the protein environment $(\varepsilon=4)$ and $7.4 \mathrm{kcal} \mathrm{mol}^{-1}$ in water $(\varepsilon=80)$ for the $\mathrm{M}^{\text {pro }}$-HID (see Figure 6) [79]. The different barriers found in the activation step for $\mathrm{M}^{\text {pro }}$-HIE $\left(17.9 \mathrm{kcal} \mathrm{mol}^{-1}\right.$ in water and $18.5 \mathrm{kcal} \mathrm{mol}^{-1}$ in protein, see Figure S15) clearly give a reason for the preferred protonation state (HID) in agreement with previous works [45-47].
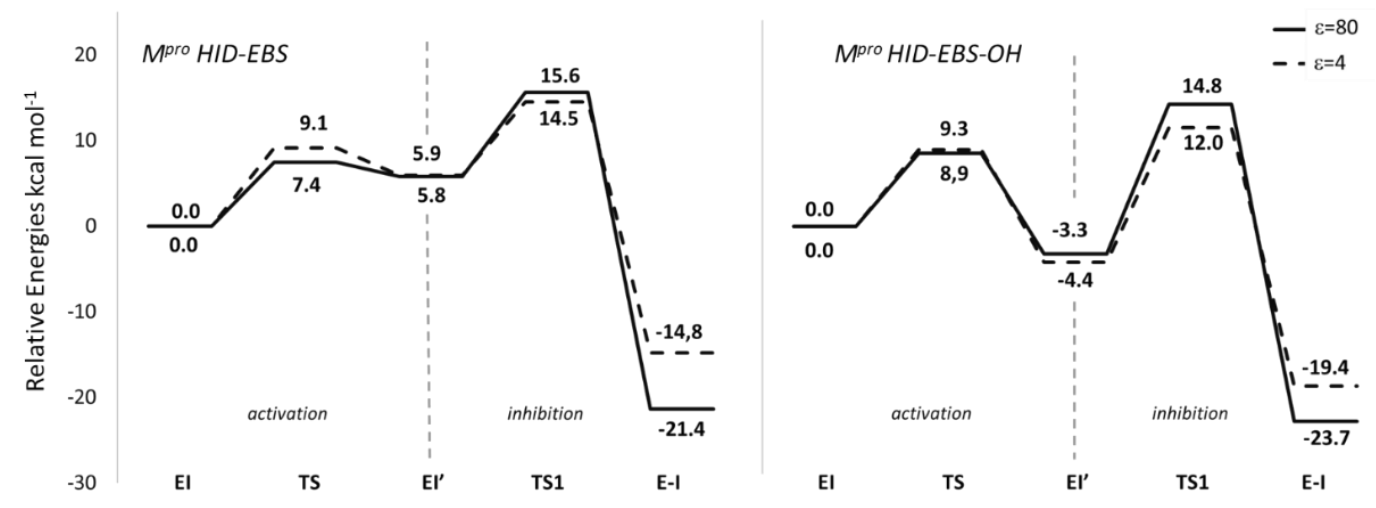

Figure 6. B3LYP-D3/6-31+G (2d,2p) free energy profiles of Mpro SARS-CoV-2 covalent inhibition mechanism by EBS and EBS-OH in two phases: activation and inhibition through covalent bond formation, expressed in $\mathrm{kcal} \mathrm{mol}^{-1}$. Solid line indicates calculations in water $(\varepsilon=80)$ and dotted line in the protein environment $(\varepsilon=4)$.

Therefore, only the inhibition process promoted by the $\mathrm{M}^{\text {pro }}$-HID has been taken into account in the case of EBS-OH (see Scheme 3).

At the end of the activation step, the $\mathrm{EI}^{\prime}$ structure, is characterized by a $\mathrm{CysS}^{-} / \mathrm{HisH}^{+}$ zwitterionic pair. Irrespective of an HIE or HID form, our calculations for ES therefore support the finding that Cys 145 of the $\mathrm{M}^{\text {pro }}$ of SARS-CoV-2 works in the neutral form and represents the resting state of the enzyme as previously noted in similar systems [71,80].

Looking at Figure 6 and Figure S15 (HIE), the EI' species representing the noncovalent complex and simultaneously the starting point of the inhibition step and having the negatively charged sulphur, is the key player of the covalent bond formation, and now lies at 2.99 (2.78) $\AA$ from selenium and at 2.15 (3.41) $\AA$ from ${\mathrm{N} \delta \mathrm{H}^{+}}\left(\mathrm{N \varepsilon} \mathrm{H}^{+}\right)$(see Figure S11). The

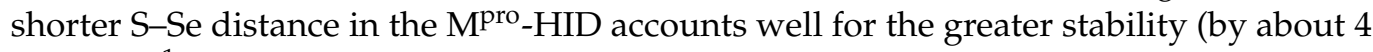
$\mathrm{kcal} \mathrm{mol}^{-1}$ ) than the corresponding species in $\mathrm{M}^{\text {pro-HIE }}$ in both considered environments (see Figure S15). 


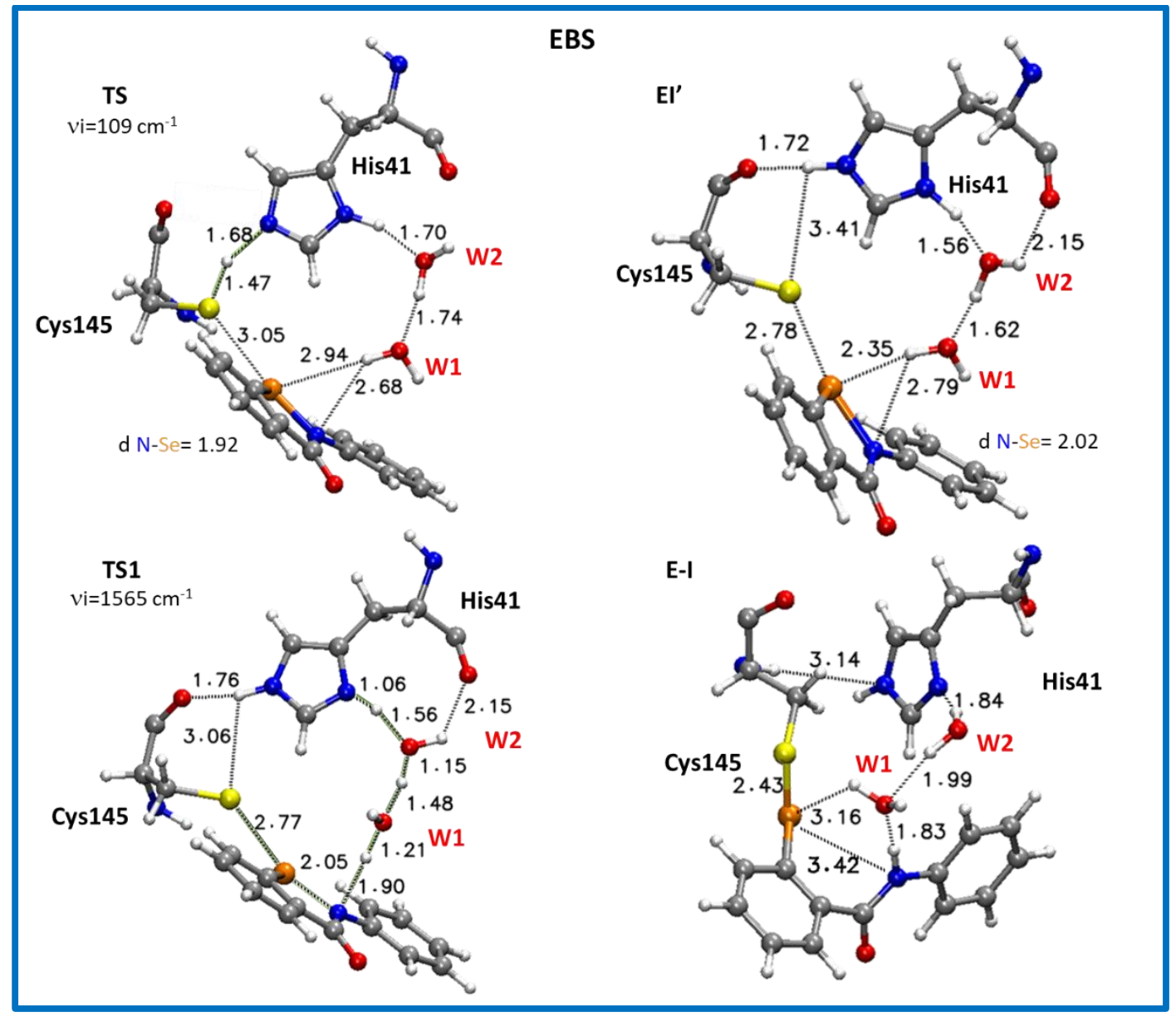

Figure 7. Optimized structures of the stationary points involved in the Mpro-HID inhibition process promoted by EBS. For clarity, only residues of the model implicated in the chemical event are shown. Main distances are in $\AA$. Imaginary frequencies are reported in $\mathrm{cm}^{-1}$ for all transition states. Cartesian coordinates of the optimized structures with the full model for these transition states as well as for the intermediates along the reaction pathway are given in the Supplementary Materials.

The Se-N “scissile" bond suffers a sensible elongation (2.02 A for both HIE and HID) making it more prone for its next cleavage.

Differently from the protease mechanisms by the Michael and peptidomimetic inhibitors investigated in recent works $[43,45,46]$, where the acylation step follows the cysteine activation, in the present case the TS1 describes the covalent bond formation triggered by a series of chemical events occurring simultaneously. These are promoted by proton transfer from the protonated His 41 mediated by W1 and W2 water molecules that cause the EBS ring opening described by the elongation of the Se-N bond in favor of the Se-S bond formation, also driven by the already present chalcogen bond (Se-S, $2.78 \AA$ ) (Figure 7). The TS1 vibrational mode mainly displays a linear stretching of these proton shifts involving the $\mathrm{N} \varepsilon$, OW2 and OW1 atoms. This hydrogen traffic, promoted by water molecules, remarks their catalytic "help", occupying the place of a third component of the triad in $\mathrm{M}^{\text {pro }}[43,44,46]$. Furthermore, the occurring ring opening in TS1 gives rise to a more negatively charged oxygen of the warhead amide moiety as evidenced by the NBO charges trend (Tables S7 and S8), although it is not directly implicated in the nucleophilic attack by the sulfur atom of Cys145 as in the proteolytic event. Due to the more negative charge assumed by the EBS oxygen (Table S6), the carbonyl moiety engages in an H-bond with the NH of the side chain of Asn142 (Figure S12) remembering the "oxyanion hole" effect in proteases. The barrier to be overcome by EI' for affording the covalent complex E-I, is 
$9.8 \mathrm{kcal} \mathrm{mol}^{-1}$ and $8.6 \mathrm{kcal} \mathrm{mol}^{-1}$ for $\varepsilon=80$ and $\varepsilon=4$, respectively (Figure 6) and compares well with the analogous S-Se bond formation previously calculated [42,81-83].

The obtained barriers however do not change the fact that the kinetics of the inhibition

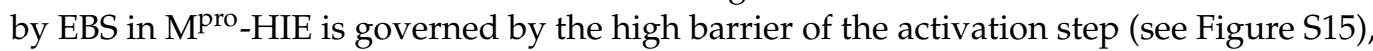
contrary to what is observed for the Michael and peptidomimetic-like inhibitors [43,45].

The final covalent product (E-I) accounts for the arrangements observed in TS1, where the S-Se bond is formed ( $2.43 \AA)$, the Se-N is now completely broken (3.38 $\AA$ ) and the neutral His41 is restored (Figure 7). The "selenosulfide intermediate nature" of the covalent product in this case, represents the stable end point, although the S-Se bond length is a little bit longer than that present in the literature for biomimetics $[40,84,85]$. This finding could be a consequence of a series of features created by the protein microenvironment (i.e., the weak interactions present in the catalytic pocket).

\subsubsection{Inhibition Promoted by EBS-OH}

On the basis of the obtained PES values reported in Figure 6, the activation step for EBS-OH requires an energetic amount of $8.9 \mathrm{kcal} \mathrm{mol}^{-1}$ and $9.3 \mathrm{kcal} \mathrm{mol}^{-1}$ in $\varepsilon=80$ and $\varepsilon=4$, respectively that is comparable with those obtained in the case of EBS (Figure 6). As previously evidenced in the starting structure EI, the TS also exhibits a distinctive interaction of EBS-OH with the carbonyl of Asn142 (1.67 $⿱$ A) using the OH moiety as a "hook" for anchoring to the side chain of the amino acid with the twisted conformation assumed by EBS-OH (Figure S13).

As a result of the activation step, the EI' noncovalent complex is formed showing the sulphur anion of the $\mathrm{CysS}^{-} / \mathrm{HisH}^{+}$zwitterionic pair at $2.81 \AA$ from its parent atom (Se) accompanied by a consequent elongation of the selenium-sulfide bond ( $2.05 \AA$ ) (Figure 8 ). The tight interaction with Asn142 mentioned above represents an important factor for the stabilization of this complex with respect to the corresponding one for EBS. In fact, for EBS-OH, the results for this species results are more stable by $3.3 \mathrm{kcal} \mathrm{mol}^{-1}(4.4 \mathrm{kcal}$ $\mathrm{mol}^{-1}$ ) in a water (protein) environment; related to the starting complex with the neutral Cys145 and His41 (Figure 6) and, as already revealed the formation of the noncovalent complex is an exothermic process. This result represents a distinguishing aspect of EBS-OH with respect to EBS, suggesting the zwitterionic form of the dyad as the most preferred one in the catalytic site of $\mathrm{M}^{\text {pro }}$-HID. The exothermicity of the $\mathrm{EI}^{\prime}$ formation evidences a better affinity of EBS-OH towards the catalytic pocket of $\mathrm{M}^{\mathrm{pro}}$, strictly related to the inhibition constant as above mentioned for Scheme 2, and this can also help to explain the greater efficiency of EBS-OH than EBS [21]. Observing the related EI' optimized structures for EBS (Figure 7) and EBS-OH (Figure 8) the only difference can be ascribed to the presence of the $\mathrm{OH}$ moiety that is involved in an H-bond with the carbonyl of Asn142 during the whole examined mechanism (Figure S13). This aspect reduces the mobility of EBS-OH versus EBS in the catalytic pocket. So, the greater stability of the EI' for EBS-OH (see Figure 6) can justify the improved inhibitory potency observed [21].

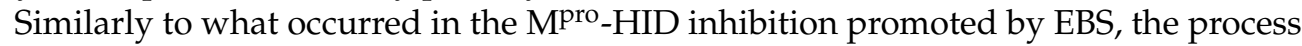
continues with the nucleophilic attack of the $S \gamma$ atoms on the selenium one and the proton transfer from the catalytic histidine to the nitrogen atom is also mediated by water molecules as depicted in the TS1 (see Figure 8). The optimized geometry offers a structure close to the covalent complex (E-I) owing to the formation of a S-Se covalent bond ( $2.57 \AA$ ) in comparison with the analogous complex in EBS (2.77 ̊̊) (Figures 7 and 8). In agreement with other studies devoted to the inhibition process of $\mathrm{M}^{\text {pro }}$ by species different from our organoselenium compounds, therein investigated $[43,45,47]$, TS1 is the rate limiting step since the barrier results, calculated to be $18.1 \mathrm{kcal} \mathrm{mol}^{-1}\left(16.4 \mathrm{kcal} \mathrm{mol}^{-1}\right)$ using $\varepsilon=80$ $(\varepsilon=4)$, are related to the previous noncovalent complex EI' (see Figure 6). 


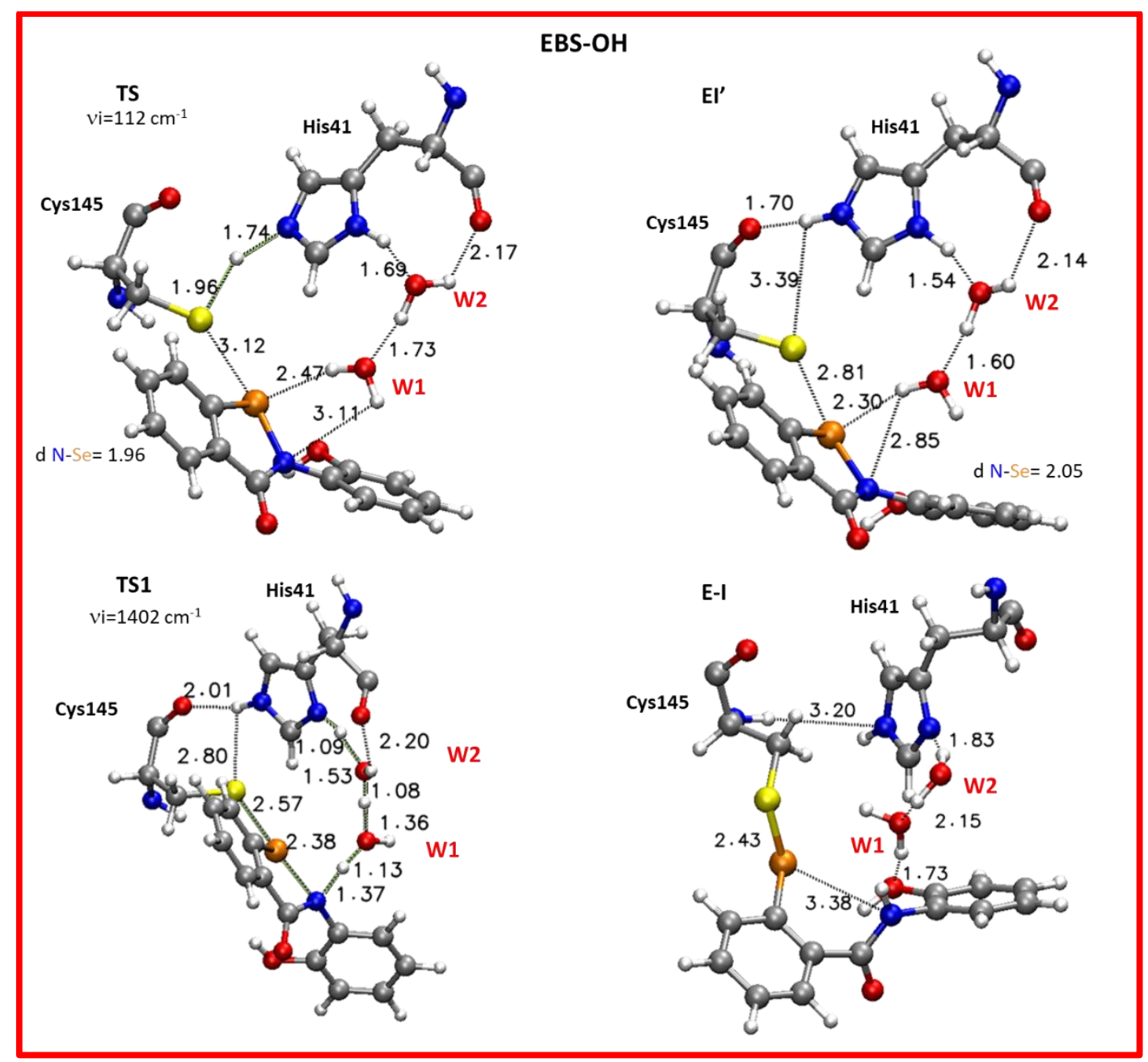

Figure 8. Optimized structures of the stationary points involved in the MPro-HID inhibition process promoted by EBS-OH. For clarity, only residues of the model implicated in the chemical event are shown. Main distances are in $\AA$. Imaginary frequencies are reported in cm-1 for all transition states. Cartesian coordinates of the optimized structures with the full model for these transition states as well as for the intermediates along the reaction pathway are given in the Supplementary Materials.

In the E-I (Figure 8) the S-Se covalent bond is $2.43 \AA$ while the distance of selenium from the nitrogen is now $3.38 \AA$. The W2 and W1 molecules are reorganized to establish the H-bond interactions with the inhibition product. From the NCI plots (Figure 9) it is also possible to evidence more extended isosurfaces attributable to vdW contributions as a consequence of the presence of the polarizing OH group with respect to EBS.

For both the considered inhibitors at the end of the inhibition process, the His41 presents a different tautomeric form from the starting complex (Scheme 2 and Schemes S1, Figures 6-8 and Figure S15). The strong stability of the E-I final complex for the covalent S-Se bond formation accounts well for the lack of observed reactivation of enzymes treated by ebselen [21] so, though the conversion between His tautomeric states is not a slow process, in the present studied inhibition it is not enough to recover the enzyme. 


\section{HIE-EBS}

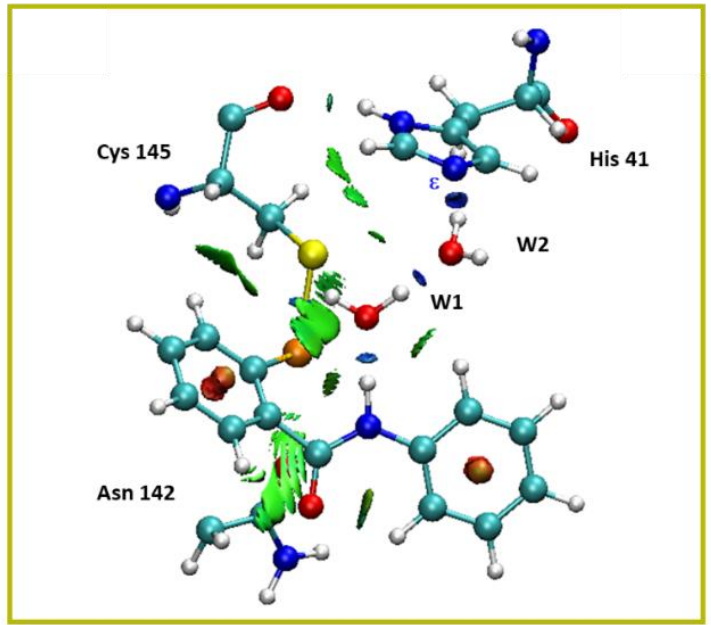

HID-EBS

HID-EBS-OH

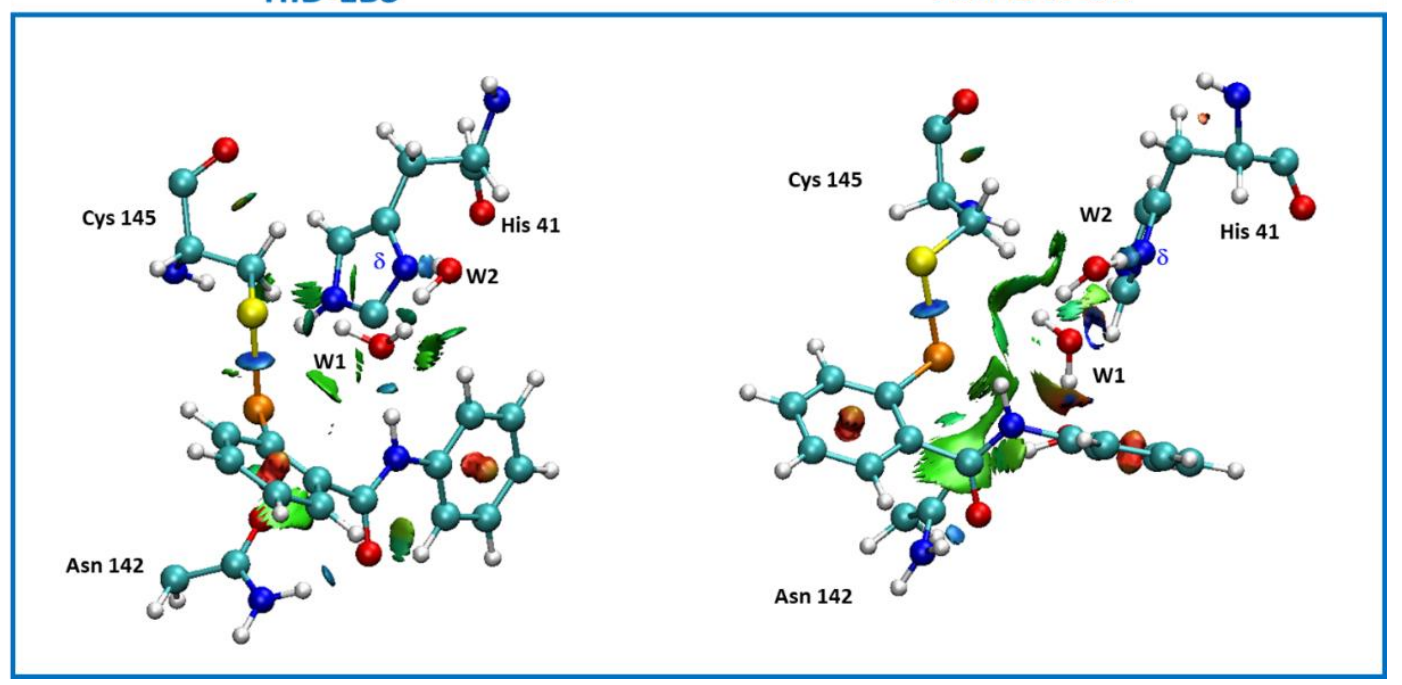

Figure 9. Noncovalent interaction plot calculated for the final covalent complex (E-I) for HIE (in yellow box) and Mpro active site HID with EBS and EBS-OH (in blue box). For clarity, only relevant residues were kept.

The inhibition rate constant of SARS-CoV-2 protease by these compounds has not been experimentally determined so it is not possible to compare the calculated barrier with any observed data. From the inhibitory potency investigated for EBS-OH with PL ${ }^{\text {pro }}$ SARS-CoV-2, an IC50 constant value of $236 \mathrm{nM}$ was found versus $2 \mu \mathrm{M}$ for ebselen. We suppose that a similar behavior could take place in the case of M ${ }^{\text {pro }}$ of SARS-CoV-2 with a half-maximal inhibitory concentration of EBS-OH better than that of EBS $(0.67 \mu \mathrm{M})$ [15]. On the basis of our results, we would expect a smaller value of EC50 for EBS-OH and therefore a more potent drug.

As can be seen from PESs (Figure 6), and the energy profiles for both EBS and EBS-OH do not suffer drastic variations based upon the effects of the two considered environments (protein and water). This is not surprising if a larger portion of the enzyme treated quantum mechanically (314 atoms) is considered. Indeed, careful systematic studies have widely demonstrated that the solvation effects of the surrounding enzyme environment decrease rapidly and even almost vanish in models with a size of around 200 atoms $[61,62,64]$. On the basis of our experience $[61,62,82,83]$, and because of the comparative nature of the present study, the QM/MM methodology is not expected to introduce a big perturbation on the mechanism but mainly an improved energetic behavior. 
That said, some deviation occurred in the case of $\varepsilon=4$ that proposes for both inhibitors a minor exothermicity of the covalent product (see Figure 6). Probably the dielectric constant value of the water tends to evidence the effects of the -OH moiety.

Since the reversibility of the reaction depends on the barrier of the reverse reaction, and with the inhibition process promoted by EBS and EBS-OH showing comparable activation barriers, the process with more exothermic results will also be more irreversible. On the

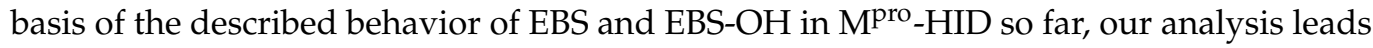
us to propose [21] EBS-OH to be an irreversible inhibitor stronger than EBS. The assumption that the reactions of irreversible inhibitors are characterized by exothermicity higher than $-22 \mathrm{kcal} \mathrm{mol}^{-1}$ [86] emphasizes our findings.

Starting from the principle that no universal rule exists for the choice of the "best" functionals, the B3LYP results for the inhibition process were benchmarked against the latest-generation density functionals, such as M06-2X, wB97X, M06, M06-2X and M08HX in order to point out an adequate level of theory to use in future investigations on the inhibition promoted by ebselen derivatives. Results are collected in Table 1. Single-point calculations were carried out on the B3LYP optimized geometries for the MPro-EBS system and the whole benchmark was limited to the ebselen inhibitor. In fact, in the case of EBS$\mathrm{OH}$, the single point calculations with the above mentioned functionals were performed only on the EI and EI' complexes due to the marked behavior of the non-covalent complex $\left(\mathrm{EI}^{\prime}\right)$ with respect to that of EBS, with its implications for the future design of possible inhibitors with improved kinetics.

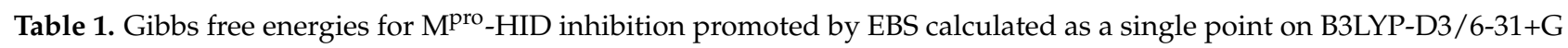
$(2 d, 2 p)$ optimized geometries in water (protein) environments. In bold, values are reported only in water, the corresponding ones for the EBS-OH inhibitor are related to the EI 'complex for the MPro-HID-EBS-OH system. All values are in $\mathrm{kcal} \mathrm{mol}^{-1}$.

\begin{tabular}{|c|c|c|c|c|c|}
\hline & B3LYP-D3 & M06 & M062X & M08HX & $\omega B 97 X$ \\
\hline EI & $0.0(0.0)$ & $0.0(0.0)$ & $0.0(0.0)$ & $0.0(0.0)$ & $0.0(0.0)$ \\
\hline TS & $7.4(9.1)$ & $7.5(7.9)$ & $6.1(9.6)$ & $0.7(2.1)$ & $0.9(3.9)$ \\
\hline $\mathrm{EI}^{\prime}$ & $5.8(5.9)-4.4$ & $0.2(3.1)-6.2$ & $0.9(2.3)-2.7$ & $2.3(1.4)-0.33$ & $-0.8(-0.9)-3.6$ \\
\hline TS1 & $15.6(14.5)$ & $11.0(13.9)$ & $9.2(12.8)$ & $8.2(11.9)$ & 10.5 (11.5) \\
\hline E-I & $-21.4(-14.8)$ & $-15.4(-12.1)$ & $-15.8(-11.7)$ & $-16.0(-12.3)$ & $-23.6(-16.2)$ \\
\hline
\end{tabular}

In general, it is noteworthy that the first step of the reaction leading to the noncovalent complex is the most sensitive to the used functionals, in particular for M08HX and $\omega \mathrm{B} 97 \mathrm{X}$, in terms of barrier heights which become low enough to suggest that the activation for obtaining the zwitterionic catalytic dyad takes place more easily and regardless of the dielectric constant value (see Table 1). All the functionals, indeed, propose a very similar stability of the EI' to that of the EI starting complex, suggesting that both the forms could be responsible for the next inhibition step.

The same does not apply for the second step of the reaction, since from the results reported in Table 1 it emerges that the B3LYP functional provides a good description of the energetics of this kind of process. This finding also gives confirmation that the effect of the dielectric constant value on the DFT cluster model calculations saturates well with increasing the system size [87], thus the cluster used appears to be adequate for this system, providing information that should be exploited to generate good candidate SARS-CoV-2 inhibitors.

The $\omega \mathrm{B} 97 \mathrm{X}$ functional (Table 1) results show it to be the best performing one as known in the literature $[63,84]$, but this does not significantly affect our findings.

In the case of EBS-OH, the exothermicity of the formation of the EI' complex is confirmed by the used functionals (see Table 1) corroborating the outcomes arising from the B3LYP investigation. 


\section{Computational Methods}

As far as the molecular dynamics simulations are concerned, a detailed description is given in the Supplementary Materials. Details on docking protocol procedure including figures (Figures S10 and S11) and table (Table S5) are given in the Supplementary Materials. The best docked pose shown in Figure S11 has been used as the starting structure for the inhibition mechanism at the QM level, and geometry optimizations were performed with a B3LYP/D3 functional [88-91] and 6-31+G basis set for all the atoms as implemented in the Gaussian 09 package [92]. To quantify the ZPE corrections, frequencies were calculated at the same level of theory, excluding the contributions of frozen atoms in the vibrational analysis [93]. To evaluate the environment effects, single-point calculations B3LYP-D3 /6$31+G(2 d, 2 p)$ in the framework of the SMD [94] model were performed on the optimized geometries by using the dielectric constants for protein $(\varepsilon=4)$ and water $(\varepsilon=80)$. The final energies reported are solvation energies arising from single point calculations with the larger basis set corrected for ZPE. In order to test if the 6-31+G basis set used was adequate for describing the inhibition phase, we conducted further calculations using $6-311+G(2 d, p)$ and AUG-cc-pVTZ basis sets and the results are reported in Table S10. These basis sets confirm the results with the smallest one, since the obtained energy barriers of the inhibition process remain essentially unchanged.

Other latest-generation functionals explicitly developed for systems with long-range

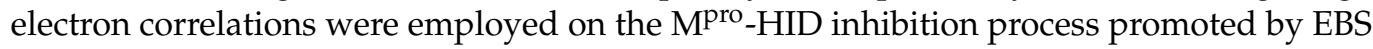
for benchmarking, such as M06 [95], M06-2X [95], $\omega B$ 97X [96], and M08HX [97], which have been recently shown to be among the best-performing density functionals in the calculations on many systems [84,85,98-100]. The M06, M06-2x and M08HX functionals usually offer good results for main-group chemistry, including thermochemistry, excitation energies, barrier heights, and noncovalent interaction energies with a better performance of M08-HX for the latter ones [101]. $\omega \mathrm{B} 97 \mathrm{X}$ belongs to the long-range-corrected functionals [96] and was revealed to be useful to better discriminate the chemistry at stake in the two phases of the inhibition mechanism. It is known that the cluster model presents some limitations, such as that a single-conformation QM cluster approach does not explicitly take into consideration the potential influence of different enzyme conformations on the reaction energetics. There is therefore, a consequent reliance on the starting structure and the use of an implicit solvent model to simulate the cluster's environment, as discussed very deeply in previous excellent papers $[7,10,64,102]$. However, it was revealed to be appropriate to study enzymatic reactions, also including their inhibition processes [60-62,65,81]. NBO [103] analysis was carried out on all the stationary points intercepted on the PESs and the related results are collected in Tables S6-S9. All the results related to the QM investigation on

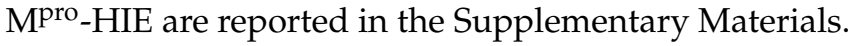

\section{Conclusions}

In the present work, the covalent inhibition of the main protease from SARS CoV-2 by repurposing organoselenium compounds, such as ebselen and its derivative on the position 2 of benzisoselenazol-3(2H)-one ring, was investigated at the QM level in the framework of density functional theory. By using a large cluster of 314 atoms our quantum chemical computations have clarified, at an atomistic level, the inhibition mechanism of two ebselen-like non-Michael acceptor covalent inhibitors of $\mathrm{M}^{\text {pro }}$. This enzyme plays a central role in the SARS-CoV-2 viral life cycle and for this reason became an attractive drug target against the COVID-19 disease. The inhibition process occurs in two steps: Cys145 is activated by His41, forming the ion pair Cys-His. The formed nucleophile species (deprotonated Cys145) performs the nucleophile attack on the selenium with the formation of the selenylsulfide bond, and takes place in concert with the ring opening promoted by the water-mediated proton delivery by His41, leading to the stable covalent enzymeinhibitor complex. The S-Se covalent bond formation, the focus of covalent inhibition and a common step of the two examined inhibitors, implies a series of the chemical events that are caught well in the stationary points intercepted through potential energy surfaces. For 
both inhibitors, the process result is irreversible even if it is more accentuated in the case of EBS-OH. Our outcomes allow us to suggest that, as already found in PL ${ }^{\text {pro }}$ SARS-CoV-2, in $\mathrm{M}^{\text {pro }}$ SARS-CoV-2, EBS-OH may result in being a more potent drug. Our calculations have provided deeper insights on the observed inhibitory potency of EBS-OH with respect to EBS as presented in the greater stability of the EI' complex relative to that of EBS. The cluster used appears to be adequate for the examined inhibition, providing information that should be exploited to generate good candidate SARS-CoV-2 inhibitors. Our results could contribute to increase the current knowledge of small-molecule covalent inhibitors and stimulate the design of drugs obtained by their incorporation into new hybrid non-Michael acceptor inhibitors. Although the winning strategy such as vaccines is available against the virus, the resource of antiviral drugs represents a helpful approach to reduce the signs of the disease caused by SARS-CoV-2 or by its variants.

Supplementary Materials: The following are available online at https:/ / www.mdpi.com/article/10 .3390/ijms22189792/s1.

Author Contributions: T.M. conceived of the presented idea and supervised the project. A.P. and I.R. performed the computations. A.P. and T.M. verified and analyzed the results. T.M. wrote the manuscript. T.M. and N.R. contributed to the final version of the manuscript. All authors have read and agreed to the published version of the manuscript.

Funding: This research received no external funding.

Acknowledgments: The authors thank the Dipartimento di Chimica e Tecnologie Chimiche of Università della Calabria for their financial support. The computing resources (in particular Visual Molecular Dynamics VMD 1.9.2) and the related technical support used for this work have been provided by CRESCO/ENEAGRID High Performance Computing infrastructure and its staff [69]. CRESCO/ENEAGRID High Performance Computing infrastructure is funded by ENEA, the Italian National Agency for New Technologies, Energy and Sustainable Economic Development and by Italian and European research programs (see http:/ / www.cresco.enea.it/english accessed on February 2021. for information).

Conflicts of Interest: The authors declare no conflict of interest. The authors declare that the research was conducted in the absence of any commercial or financial relationships that could be construed as a potential conflict of interest.

\section{References}

1. Chen, N.; Zhou, M.; Dong, X.; Qu, J.; Gong, F.; Han, Y.; Qiu, Y.; Wang, J.; Liu, Y.; Wei, Y.; et al. Epidemiological and clinical characteristics of 99 cases of 2019 novel coronavirus pneumonia in Wuhan, China: A descriptive study. Lancet 2020, 395, 507-513. [CrossRef]

2. Hui, D.S.; Zumla, P.S.A. Severe Acute Respiratory Syndrome: Historical, Epidemiologic, and Clinical Features. Infect. Dis. Clin. N. Am. 2019, 33, 869-889. [CrossRef] [PubMed]

3. Wrapp, D.; Wang, N.; Corbett, K.S.; Goldsmith, J.A.; Hsieh, C.-L.; Abiona, O.; Graham, B.S.; McLellan, J.S. Cryo-EM structure of the 2019-nCoV spike in the prefusion conformation. Science 2020, 367, 1260-1263. [CrossRef] [PubMed]

4. Woo, P.C.Y.; Huang, Y.; Lau, S.K.P.; Yuen, K.-Y. Coronavirus Genomics and Bioinformatics Analysis. Viruses 2010, 2, 1804-1820. [CrossRef]

5. Walls, A.C.; Park, Y.-J.; Tortorici, M.A.; Wall, A.; McGuire, A.T.; Veesler, D. Structure, Function, and Antigenicity of the SARS-CoV-2 Spike Glycoprotein. Cell 2020, 181, 281-292.e6. [CrossRef]

6. Pillaiyar, T.; Manickam, M.; Namasivayam, V.; Hayashi, Y.; Jung, S.-H. An Overview of Severe Acute Respiratory SyndromeCoronavirus (SARS-CoV) 3CL Protease Inhibitors: Peptidomimetics and Small Molecule Chemotherapy. J. Med. Chem. 2016, 59, 6595-6628. [CrossRef]

7. Yang, H.; Xie, W.; Xue, X.; Yang, K.; Ma, J.; Liang, W.; Zhao, Q.; Zhou, Z.; Pei, D.; Ziebuhr, J.; et al. Design of Wide-Spectrum Inhibitors Targeting Coronavirus Main Proteases. PLoS Biol. 2005, 3, e324. [CrossRef]

8. Anand, K.; Ziebuhr, J.; Wadhwani, P.; Mesters, J.R.; Hilgenfeld, R. Coronavirus Main Proteinase (3CLpro) Structure: Basis for Design of Anti-SARS Drugs. Science 2003, 300, 1763-1767. [CrossRef] [PubMed]

9. Ren, Z.; Yan, L.; Zhang, N.; Guo, Y.; Yang, C.; Lou, Z.; Rao, Z. The newly emerged SARS-Like coronavirus HCoV-EMC also has an "Achilles' heel": Current effective inhibitor targeting a 3C-like protease. Protein Cell 2013, 4, 248-250. [CrossRef]

10. Anand, K.; Palm, G.J.; Mesters, J.R.; Siddell, S.G.; Ziebuhr, J.; Hilgenfeld, R. Structure of coronavirus main proteinase reveals combination of a chymotrypsin fold with an extra alpha-helical domain. EMBO J. 2002, 21, 3213-3224. [CrossRef]

11. Ullrich, S.; Nitsche, C. The SARS-CoV-2 Main Protease as Drug Target. Bioorganic Med. Chem. Lett. 2020, 30, 127377. [CrossRef] 
12. Verma, N.; Henderson, J.A.; Shen, J. Proton-Coupled Conformational Activation of SARS Coronavirus Main Proteases and Opportunity for Designing Small-Molecule Broad-Spectrum Targeted Covalent Inhibitors. J. Am. Chem. Soc. 2020, 142, 2188321890. [CrossRef] [PubMed]

13. Citarella, A.; Scala, A.; Piperno, A.; Micale, N. SARS-CoV-2 Mpro: A Potential Target for Peptidomimetics and Small-Molecule Inhibitors. Biomolecules 2021, 11, 607. [CrossRef]

14. Mengist, H.M.; Dilnessa, T.; Jin, T. Structural Basis of Potential Inhibitors Targeting SARS-CoV-2 Main Protease. Front. Chem. 2021, 9, 622898. [CrossRef]

15. Jin, Z.; Du, X.; Xu, Y.; Deng, Y.; Liu, M.; Zhao, Y.; Zhang, B.; Li, X.; Zhang, L.; Peng, C.; et al. Structure of Mpro from SARS-CoV-2 and discovery of its inhibitors. Nature 2020, 582, 289-293. [CrossRef]

16. Haritha, C.; Sharun, K.; Jose, B. Ebselen, a new candidate therapeutic against SARS-CoV-2. Int. J. Surg. 2020, 84, 53-56. [CrossRef] [PubMed]

17. Menéndez, C.A.; Byléhn, F.; Perez-Lemus, G.R.; Alvarado, W.; De Pablo, J.J. Molecular characterization of ebselen binding activity to SARS-CoV-2 main protease. Sci. Adv. 2020, 6, eabd0345. [CrossRef]

18. Sies, H.; Parnham, M.J. Potential therapeutic use of ebselen for COVID-19 and other respiratory viral infections. Free. Radic. Biol. Med. 2020, 156, 107-112. [CrossRef]

19. Banerjee, R.; Perera, L.; Tillekeratne, L.V. Potential SARS-CoV-2 main protease inhibitors. Drug Discov. Today 2020, 26, 804-816. [CrossRef] [PubMed]

20. Goins, C.M.; Dajnowicz, S.; Thanna, S.; Sucheck, S.J.; Parks, J.M.; Ronning, D.R. Exploring Covalent Allosteric Inhibition of Antigen 85C from Mycobacterium tuberculosis by Ebselen Derivatives. ACS Infect. Dis. 2017, 3, 378-387. [CrossRef] [PubMed]

21. Weglarz-Tomczak, E.; Tomczak, J.M.; Talma, M.; Burda-Grabowska, M.; Giurg, M.; Brul, S. Identification of ebselen and its analogues as potent covalent inhibitors of papain-like protease from SARS-CoV-2. Sci. Rep. 2021, 11, 1-10. [CrossRef]

22. Parnham, M.; Sies, H. Ebselen: Prospective therapy for cerebral ischaemia. Expert Opin. Investig. Drugs 2000, 9, 607-619. [CrossRef]

23. Schewe, T. Molecular actions of Ebselen-An antiinflammatory antioxidant. Gen. Pharmacol. Vasc. Syst. 1995, 26, 1153-1169. [CrossRef]

24. Favrot, L.; Grzegorzewicz, A.E.; Lajiness, D.H.; Marvin, R.K.; Boucau, J.; Isailovic, D.; Jackson, M.; Ronning, D.R. Mechanism of inhibition of Mycobacterium tuberculosis antigen 85 by ebselen. Nat. Commun. 2013, 4, 1-10. [CrossRef]

25. Bzówka, M.; Mitusińska, K.; Raczyńska, A.; Samol, A.; Tuszyński, J.A.; Góra, A. Structural and Evolutionary Analysis Indicate That the SARS-CoV-2 Mpro Is a Challenging Target for Small-Molecule Inhibitor Design. Int. J. Mol. Sci. 2020, 21, 3099. [CrossRef]

26. Singh, N.; Halliday, A.C.; Thomas, J.M.; Kuznetsova, O.V.; Baldwin, R.; Woon, E.; Aley, P.K.; Antoniadou, I.; Sharp, T.; Vasudevan, S.R.; et al. A safe lithium mimetic for bipolar disorder. Nat. Commun. 2013, 4, 1-7. [CrossRef]

27. Kil, J.; Lobarinas, E.; Spankovich, C.; Griffiths, S.K.; Antonelli, P.J.; Lynch, E.D.; Le Prell, C. Safety and efficacy of ebselen for the prevention of noise-induced hearing loss: A randomised, double-blind, placebo-controlled, phase 2 trial. Lancet 2017, 390, 969-979. [CrossRef]

28. Singh, N.; Sharpley, A.L.; Emir, U.; Masaki, C.; Herzallah, M.; Gluck, M.A.; Sharp, T.; Harmer, C.; Vasudevan, S.R.; Cowen, P.; et al. Effect of the Putative Lithium Mimetic Ebselen on Brain Myo-Inositol, Sleep, and Emotional Processing in Humans. Neuropsychopharmacology 2015, 41, 1768-1778. [CrossRef] [PubMed]

29. Kil, J.; Pierce, C.; Tran, H.; Gu, R.; Lynch, E.D. Ebselen treatment reduces noise induced hearing loss via the mimicry and induction of glutathione peroxidase. Hear. Res. 2007, 226, 44-51. [CrossRef] [PubMed]

30. Zheng, W.; He, R.; Boada, R.; Subirana, M.A.; Ginman, T.; Ottosson, H.; Valiente, M.; Zhao, Y.; Hassan, M. A general covalent binding model between cytotoxic selenocompounds and albumin revealed by mass spectrometry and X-ray absorption spectroscopy. Sci. Rep. 2020, 10, 1-10. [CrossRef]

31. Thenin-Houssier, S.; de Vera, I.M.S.; Pedro-Rosa, L.; Brady, A.; Richard, A.; Konnick, B.; Opp, S.; Buffone, C.; Fuhrmann, J.; Kota, S.; et al. Ebselen, a Small-Molecule Capsid Inhibitor of HIV-1 Replication. Antimicrob. Agents Chemother. 2016, 60, $2195-2208$. [CrossRef] [PubMed]

32. De Munnik, M.; Lohans, C.T.; Lang, P.A.; Langley, G.; Malla, T.R.; Tumber, A.; Schofield, C.J.; Brem, J. Targeting the Mycobacterium tuberculosis transpeptidase LdtMt2 with cysteine-reactive inhibitors including ebselen. Chem. Commun. 2019, 55, 10214-10217. [CrossRef]

33. Bender, K.O.; Garland, M.; Ferreyra, J.A.; Hryckowian, A.J.; Child, M.; Puri, A.W.; Solow-Cordero, D.; Higginbottom, S.K.; Segal, E.; Banaei, N.; et al. A small-molecule antivirulence agent for treatingClostridium difficileinfection. Sci. Transl. Med. 2015, 7, 306ra148. [CrossRef]

34. Mukherjee, S.; Weiner, W.S.; Schroeder, C.E.; Simpson, D.S.; Hanson, A.M.; Sweeney, N.L.; Marvin, R.K.; Ndjomou, J.; Kolli, R.; Isailovic, D.; et al. Ebselen Inhibits Hepatitis C Virus NS3 Helicase Binding to Nucleic Acid and Prevents Viral Replication. ACS Chem. Biol. 2014, 9, 2393-2403. [CrossRef] [PubMed]

35. Nikawa, T.; Schuch, G.; Wagner, G.; Sies, H. Interaction of ebselen with glutathione S-transferase and papain in vitro. Biochem. Pharmacol. 1994, 47, 1007-1012. [CrossRef]

36. Azad, G.; Singh, V.; Mandal, P.; Singh, P.; Golla, U.R.; Baranwal, S.; Chauhan, S.; Tomar, R.S. Ebselen induces reactive oxygen species (ROS)-mediated cytotoxicity inSaccharomyces cerevisiaewith inhibition of glutamate dehydrogenase being a target. FEBS Open Bio 2014, 4, 77-89. [CrossRef] [PubMed] 
37. Zmudzinski, M.; Rut, W.; Olech, K.; Granda, J.; Giurg, M.; Burda-Grabowska, M.; Zhang, L.; Sun, X.; Lv, Z.; Nayak, D.; et al. Ebselen Derivatives Are Very Potent Dual Inhibitors of SARS-CoV-2 Proteases-PLpro and Mpro in in Vitro Studies. bioRxiv 2020. [CrossRef]

38. Ma, C.; Hu, Y.; Townsend, J.A.; Lagarias, P.I.; Marty, M.T.; Kolocouris, A.; Wang, J. Ebselen, Disulfiram, Carmofur, PX-12, Tideglusib, and Shikonin Are Nonspecific Promiscuous SARS-CoV-2 Main Protease Inhibitors. ACS Pharmacol. Transl. Sci. 2020, 3 , 1265-1277. [CrossRef]

39. Weglarz-Tomczak, E.; Tomczak, J.M.; Giurg, M.; Burda-Grabowska, M.; Brul, S. Discovery of Potent Inhibitors of PLproCoV2 by Screening a Library of Selenium-Containing Compounds. bioRxiv 2020. [CrossRef]

40. Cerqueira, N.M.F.S.A.; Fernandes, P.A.; Gonzalez, P.J.; Moura, J.J.G.; Ramos, M.J. The Sulfur Shift: An Activation Mechanism for Periplasmic Nitrate Reductase and Formate Dehydrogenase. Inorg. Chem. 2013, 52, 10766-10772. [CrossRef]

41. Cheng, Q.; Sandalova, T.; Lindqvist, Y.; Arnér, E. Crystal Structure and Catalysis of the Selenoprotein Thioredoxin Reductase 1. J. Biol. Chem. 2009, 284, 3998-4008. [CrossRef]

42. Fortino, M.; Marino, T.; Russo, N.; Sicilia, E. Mechanism of Thyroxine Deiodination by Naphthyl-Based Iodothyronine Deiodinase Mimics and the Halogen Bonding Role: A DFT Investigation. Chem.-Eur. J. 2015, 21, 8554-8560. [CrossRef]

43. Mondal, D.; Warshel, A. Exploring the Mechanism of Covalent Inhibition: Simulating the Binding Free Energy of $\alpha$-Ketoamide Inhibitors of the Main Protease of SARS-CoV-2. Biochemistry 2020, 59, 4601-4608. [CrossRef]

44. Świderek, K.; Moliner, V. Revealing the molecular mechanisms of proteolysis of SARS-CoV-2 Mproby QM/MM computational methods. Chem. Sci. 2020, 11, 10626-10630. [CrossRef]

45. Arafet, K.; Serrano-Aparicio, N.; Lodola, A.; Mulholland, A.J.; González, F.V.; Świderek, K.; Moliner, V. Mechanism of inhibition of SARS-CoV-2 Mpro by N3 peptidyl Michael acceptor explained by QM/MM simulations and design of new derivatives with tunable chemical reactivity. Chem. Sci. 2021, 12, 1433-1444. [CrossRef]

46. Ramos-Guzmán, C.A.; Ruiz-Pernía, J.J.; Tunón, I. Multiscale Simulations of SARS-CoV-2 3CL Protease Inhibition with Aldehyde Derivatives. Role of Protein and Inhibitor Conformational Changes in the Reaction Mechanism. ACS Catal. 2021, 11, 4157-4168. [CrossRef] [PubMed]

47. Ramos-Guzmán, C.A.; Ruiz-Pernía, J.J.; Tuñón, I. A microscopic description of SARS-CoV-2 main protease inhibition with Michael acceptors. Strategies for improving inhibitor design. Chem. Sci. 2021, 12, 3489-3496. [CrossRef] [PubMed]

48. Pavlova, A.; Lynch, D.L.; Daidone, I.; Zanetti-Polzi, L.; Smith, M.D.; Chipot, C.; Kneller, D.W.; Kovalevsky, A.; Coates, L.; Golosov, A.A.; et al. Inhibitor binding influences the protonation states of histidines in SARS-CoV-2 main protease. Chem. Sci. 2021, 12, 1513-1527. [CrossRef]

49. Zanetti-Polzi, L.; Smith, M.D.; Chipot, C.; Gumbart, J.C.; Lynch, D.L.; Pavlova, A.; Smith, J.C.; Daidone, I. Tuning Proton Transfer Thermodynamics in SARS-Cov-2 Main Protease: Implications for Catalysis and Inhibitor Design. ChemRxiv Prepr. Serv. Chem. 2020, 12, 1513-1527. [CrossRef]

50. Zhang, L.; Lin, D.; Sun, X.; Curth, U.; Drosten, C.; Sauerhering, L.; Becker, S.; Rox, K.; Hilgenfeld, R. Crystal Structure of SARS CoV-2 Main Protease Provides a Basis for Design of Improved a-Ketoamide Inhibitors. Science 2020, 368, 409-412. [CrossRef] [PubMed]

51. Kneller, D.W.; Phillips, G.; O’Neill, H.M.; Jedrzejczak, R.; Stols, L.; Langan, P.; Joachimiak, A.; Coates, L.; Kovalevsky, A. Structural plasticity of SARS-CoV-2 3CL Mpro active site cavity revealed by room temperature X-ray crystallography. Nat. Commun. 2020, 11, 1-6. [CrossRef]

52. Hung, H.C.; Ke, Y.Y.; Huang, S.Y.; Huang, P.N.; Kung, Y.A.; Chang, T.Y.; Yen, K.J.; Peng, T.T.; Chang, S.E.; Huang, C.T.; et al. Discovery of M Protease Inhibitors Encoded by SARS-CoV-2. Antimicrob. Agents Chemother. 2020, 64, e00872-20. [CrossRef]

53. Rathnayake, A.D.; Zheng, J.; Kim, Y.; Perera, K.D.; Mackin, S.; Meyerholz, D.K.; Kashipathy, M.M.; Battaile, K.P.; Lovell, S.; Perlman, S.; et al. 3C-like protease inhibitors block coronavirus replication in vitro and improve survival in MERS-CoV-infected mice. Sci. Transl. Med. 2020, 12, eabc5332. [CrossRef] [PubMed]

54. Ma, C.; Sacco, M.D.; Hurst, B.; Townsend, J.A.; Hu, Y.; Szeto, T.; Zhang, X.; Tarbet, B.; Marty, M.; Chen, Y.; et al. Boceprevir, GC-376, and calpain inhibitors II, XII inhibit SARS-CoV-2 viral replication by targeting the viral main protease. Cell Res. 2020, 30, 678-692. [CrossRef]

55. Jin, Z.; Zhao, Y.; Sun, Y.; Zhang, B.; Wang, H.; Wu, Y.; Zhu, Y.; Zhu, C.; Hu, T.; Du, X.; et al. Structural basis for the inhibition of SARS-CoV-2 main protease by antineoplastic drug carmofur. Nat. Struct. Mol. Biol. 2020, 27, 529-532. [CrossRef] [PubMed]

56. Structure of SARS-CoV-2 Main Protease Bound to Potent Broad-Spectrum Non-Covalent Inhibitor X77. 2020. Available online: https:/ / www.wwpdb.org/pdb?id=pdb_00006w63 (accessed on 25 March 2020).

57. Paasche, A.; Zipper, A.; Schäfer, S.; Ziebuhr, J.; Schirmeister, T.; Engels, B. Evidence for Substrate Binding-Induced Zwitterion Formation in the Catalytic Cys-His Dyad of the SARS-CoV Main Protease. Biochemistry 2014, 53, 5930-5946. [CrossRef]

58. Paasche, A.; Schirmeister, T.; Engels, B. Benchmark Study for the Cysteine-Histidine Proton Transfer Reaction in a Protein Environment: Gas Phase, COSMO, QM/MM Approaches. J. Chem. Theory Comput. 2013, 9, 1765-1777. [CrossRef]

59. Baker, N.A.; Sept, D.; Joseph, S.; Holst, M.J.; McCammon, J.A. Electrostatics of nanosystems: Application to microtubules and the ribosome. Proc. Natl. Acad. Sci. USA 2001, 98, 10037-10041. [CrossRef]

60. Prejanò, M.; Medina, F.E.; Fernandes, P.; Russo, N.; Ramos, M.J.; Marino, T. The Catalytic Mechanism of Human Transketolase. ChemPhysChem 2019, 20, 2881-2886. [CrossRef] [PubMed] 
61. Prejanò, M.; Romeo, I.; Sgrizzi, L.; Russo, N.; Marino, T. Why hydroxy-proline improves the catalytic power of the peptidoglycan N-deacetylase enzyme: Insight from theory. Phys. Chem. Chem. Phys. 2019, 21, 23338-23345. [CrossRef]

62. Parise, A.; Russo, N.; Marino, T. The RNase A Platination Process by Arsenoplatin: Insights from Theoretical Study. Inorg. Chem. Front. 2021, 8, 1795-1803. [CrossRef]

63. Neves, R.P.P.; Fernandes, P.; Ramos, M.J. Mechanistic insights on the reduction of glutathione disulfide by protein disulfide isomerase. Proc. Natl. Acad. Sci. USA 2017, 114, E4724-E4733. [CrossRef] [PubMed]

64. Blomberg, M.R.A.; Borowski, T.; Himo, F.; Liao, R.-Z.; Siegbahn, P.E.M. Quantum Chemical Studies of Mechanisms for Metalloenzymes. Chem. Rev. 2014, 114, 3601-3658. [CrossRef] [PubMed]

65. Himo, F. Recent Trends in Quantum Chemical Modeling of Enzymatic Reactions. J. Am. Chem. Soc. 2017, 139, 6780-6786. [CrossRef] [PubMed]

66. Siegbahn, P.E.M.; Himo, F. Recent developments of the quantum chemical cluster approach for modeling enzyme reactions. JBIC J. Biol. Inorg. Chem. 2009, 14, 643-651. [CrossRef]

67. Ziebuhr, J. Molecular biology of severe acute respiratory syndrome coronavirus. Curr. Opin. Microbiol. 2004, 7, 412-419. [CrossRef]

68. Ho, B.-L.; Cheng, S.-C.; Shi, L.; Wang, T.-Y.; Ho, K.-I.; Chou, C.-Y. Critical Assessment of the Important Residues Involved in the Dimerization and Catalysis of MERS Coronavirus Main Protease. PLoS ONE 2015, 10, e0144865. [CrossRef] [PubMed]

69. Awoonor-Williams, E.; Rowley, C.N. Evaluation of Methods for the Calculation of the pKa of Cysteine Residues in Proteins. J. Chem. Theory Comput. 2016, 12, 4662-4673. [CrossRef]

70. Arafet, K.; González, F.V.; Moliner, V. Quantum Mechanics/Molecular Mechanics Studies of the Mechanism of Cysteine Proteases Inhibition by Dipeptidyl Nitroalkenes. Chem.-Eur. J. 2020, 26, 2002-2012. [CrossRef]

71. Silva, J.R.A.; Cianni, L.; Araujo, D.; Batista, P.H.J.; de Vita, D.; Rosini, F.; Leitao, A.; Lameira, J.; Montanari, C.A. Assessment of the Cruzain Cysteine Protease Reversible and Irreversible Covalent Inhibition Mechanism. J. Chem. Inf. Model. 2020, 60, $1666-1677$. [CrossRef]

72. Arafet, K.; Ferrer, S.; Moliner, V. Computational Study of the Catalytic Mechanism of the Cruzain Cysteine Protease. ACS Catal. 2017, 7, 1207-1215. [CrossRef]

73. Anandakrishnan, R.; Aguilar, B.; Onufriev, A.V. H++ 3.0: Automating pK prediction and the preparation of biomolecular structures for atomistic molecular modeling and simulations. Nucleic Acids Res. 2012, 40, W537-W541. [CrossRef]

74. Roos, G.; Foloppe, N.; Messens, J. Understanding the pKa of Redox Cysteines: The Key Role of Hydrogen Bonding. Antioxid. Redox Signal. 2013, 18, 94-127. [CrossRef]

75. Cianni, L.; Feldmann, C.W.; Gilberg, E.; Gütschow, M.; Juliano, L.; Leitao, A.; Bajorath, J.; Montanari, C.A. Can Cysteine Protease Cross-Class Inhibitors Achieve Selectivity? J. Med. Chem. 2019, 62, 10497-10525. [CrossRef] [PubMed]

76. Quesne, M.G.; Ward, R.A.; De Visser, S.P. Cysteine protease inhibition by nitrile-based inhibitors: A computational study. Front. Chem. 2013, 1, 39. [CrossRef]

77. Batra, J.; Szabo, A.; Caulfield, T.R.; Soares, A.S.; Sahin-Tóth, M.; Radisky, E.S. Long-range Electrostatic Complementarity Governs Substrate Recognition by Human Chymotrypsin C, a Key Regulator of Digestive Enzyme Activation. J. Biol. Chem. 2013, 288, 9848-9859. [CrossRef]

78. Kumar, P.; Agarwal, P.K.; Waddell, M.B.; Mittag, T.; Serpersu, E.H.; Cuneo, M.J. Low-Barrier and Canonical Hydrogen Bonds Modulate Activity and Specificity of a Catalytic Triad. Angew. Chem. Int. Ed. 2019, 58, 16260-16266. [CrossRef] [PubMed]

79. Rut, W.; Groborz, K.; Zhang, L.; Sun, X.; Zmudzinski, M.; Pawlik, B.; Młynarski, W.; Hilgenfeld, R.; Drag, M. Substrate Specificity Profiling of SARS-CoV-2 Main Protease Enables Design of Activity-Based Probes for Patient-Sample Imaging. bioRxiv 2020. [CrossRef]

80. Prejanò, M.; Romeo, I.; Russo, N.; Marino, T. On the Catalytic Activity of the Engineered Coiled-Coil Heptamer Mimicking the Hydrolase Enzymes: Insights from a Computational Study. Int. J. Mol. Sci. 2020, 21, 4551. [CrossRef] [PubMed]

81. Prejanò, M.; Marino, T.; Russo, N. On the Inhibition Mechanism of Glutathione Transferase P1 by Piperlongumine. Insight From Theory. Front. Chem. 2018, 6, 606. [CrossRef]

82. Prejanò, M.; Medina, F.E.; Ramos, M.J.; Russo, N.; Fernandes, P.; Marino, T. How the Destabilization of a Reaction Intermediate Affects Enzymatic Efficiency: The Case of Human Transketolase. ACS Catal. 2020, 10, 2872-2881. [CrossRef]

83. Piazzetta, P.; Marino, T.; Russo, N. Promiscuous Ability of Human Carbonic Anhydrase: QM and QM/MM Investigation of Carbon Dioxide and Carbodiimide Hydration. Inorg. Chem. 2014, 53, 3488-3493. [CrossRef]

84. Tolbatov, I.; Coletti, C.; Marrone, A.; Re, N. Insight into the Substitution Mechanism of Antitumor Au(I) N-Heterocyclic Carbene Complexes by Cysteine and Selenocysteine. Inorg. Chem. 2020, 59, 3312-3320. [CrossRef] [PubMed]

85. Nikoo, S.; Meister, P.J.; Hayward, J.J.; Gauld, J.W. An Assessment of Computational Methods for Calculating Accurate Structures and Energies of Bio-Relevant Polysulfur/Selenium-Containing Compounds. Molecules 2018, 23, 3323. [CrossRef]

86. Mladenovic, M.; Ansorg, K.; Fink, R.F.; Thiel, W.; Schirmeister, T.; Engels, B. Atomistic Insights into the Inhibition of Cysteine Proteases: First QM/MM Calculations Clarifying the Stereoselectivity of Epoxide-Based Inhibitors. J. Phys. Chem. B 2008, 112, 11798-11808. [CrossRef] [PubMed]

87. Liao, R.-Z.; Yu, J.-G.; Himo, F. Quantum Chemical Modeling of Enzymatic Reactions: The Case of Decarboxylation. J. Chem. Theory Comput. 2011, 7, 1494-1501. [CrossRef] [PubMed]

88. Lee, C.; Yang, W.; Parr, R.G. Development of the Colle-Salvetti correlation-energy formula into a functional of the electron density. Phys. Rev. B 1988, 37, 785-789. [CrossRef] 
89. Becke, A.D. Density-functional thermochemistry. III. The role of exact exchange. J. Chem. Phys. 1993, 98, 5648-5652. [CrossRef]

90. Grimme, S.; Antony, J.; Ehrlich, S.; Krieg, H. A consistent and accurate ab initio parametrization of density functional dispersion correction (DFT-D) for the 94 elements H-Pu. J. Chem. Phys. 2010, 132, 154104. [CrossRef]

91. Grimme, S. Supramolecular Binding Thermodynamics by Dispersion-Corrected Density Functional Theory. Chem.—Eur. J. 2012, 18, 9955-9964. [CrossRef]

92. Frisch, M.J.; Trucks, G.W.; Schlegel, H.B.; Scuseria, G.E.; Robb, M.A.; Cheeseman, J.R.; Scalmani, G.; Barone, V.; Mennucci, B.; Petersson, G.A.; et al. Gaussian 09; Revision D.01; Gaussian, Inc.: Wallingford, CT, USA, 2013.

93. Yan, J.; Chen, S. How to Produce Methane Precursor in the Upper Ocean by an Untypical Non-Heme Fe-Dependent Methylphosphonate Synthase? ChemPhysChem 2020, 21, 385-396. [CrossRef]

94. Marenich, A.V.; Cramer, C.; Truhlar, D. Universal Solvation Model Based on Solute Electron Density and on a Continuum Model of the Solvent Defined by the Bulk Dielectric Constant and Atomic Surface Tensions. J. Phys. Chem. B 2009, 113, $6378-6396$. [CrossRef] [PubMed]

95. Zhao, Y.; Truhlar, D.G. The M06 suite of density functionals for main group thermochemistry, thermochemical kinetics, noncovalent interactions, excited states, and transition elements: Two new functionals and systematic testing of four M06-class functionals and 12 other functionals. Theor. Chem. Accounts 2008, 120, 215-241. [CrossRef]

96. Chai, J.-D.; Head-Gordon, M. Long-range corrected hybrid density functionals with damped atom-atom dispersion corrections. Phys. Chem. Chem. Phys. 2008, 10, 6615-6620. [CrossRef]

97. Zhao, Y.; Truhlar, D. Exploring the Limit of Accuracy of the Global Hybrid Meta Density Functional for Main-Group Thermochemistry, Kinetics, and Noncovalent Interactions. J. Chem. Theory Comput. 2008, 4, 1849-1868. [CrossRef] [PubMed]

98. Minenkov, Y.; Singstad, Å.; Occhipinti, G.; Jensen, V.R. The accuracy of DFT-optimized geometries of functional transition metal compounds: A validation study of catalysts for olefin metathesis and other reactions in the homogeneous phase. Dalton Trans. 2012, 41, 5526-5541. [CrossRef]

99. Qi, S.-C.; Hayashi, J.-I.; Zhang, L. Recent application of calculations of metal complexes based on density functional theory. RSC Adv. 2016, 6, 77375-77395. [CrossRef]

100. Mardirossian, N.; Head-Gordon, M. How Accurate Are the Minnesota Density Functionals for Noncovalent Interactions, Isomerization Energies, Thermochemistry, and Barrier Heights Involving Molecules Composed of Main-Group Elements? J. Chem. Theory Comput. 2016, 12, 4303-4325. [CrossRef]

101. Wang, Y.; Verma, P.; Jin, X.; Truhlar, D.G.; He, X. Revised M06 density functional for main-group and transition-metal chemistry. Proc. Natl. Acad. Sci. USA 2018, 115, 10257-10262. [CrossRef]

102. Huggins, D.J.; Biggin, P.C.; Dämgen, M.A.; Essex, J.W.; Harris, S.A.; Henchman, R.H.; Khalid, S.; Kuzmanic, A.; Laughton, C.A.; Michel, J.; et al. Biomolecular simulations: From dynamics and mechanisms to computational assays of biological activity. Wiley Interdiscip. Rev. Comput. Mol. Sci. 2019, 9, e1393. [CrossRef]

103. Glendening, E.D.; Reed, A.E.; Carpenter, J.E.; Weinhold, F. NBO, version 3.1; Theoretical Chemistry Institute, University of Wisconsin: Madison, WI, USA, 1995. 